\title{
Experts' memory: an ERP study of perceptual expertise effects on encoding and recognition
}

\author{
Grit Herzmann • Tim Curran
}

Published online: 25 November 2010

(C) Psychonomic Society, Inc. 2010

\begin{abstract}
This study examined how perceptual expertise facilitates encoding and recognition. The electroencephalogram of car experts and car novices was recorded in the study as well as test phases of a remember/know task with car and bird stimuli. Car expertise influenced performance and eventrelated potentials (ERPs) for cars but not birds. Experts recognized and "recollected" cars more accurately, while novices had more false alarms. The ERPs provided neural evidence for theoretical assumptions about expert memory. Memory encoding in the study phase was less effortful and more elaborate for experts than novices, as indicated by lower mean amplitudes for subsequently "recollected" cars and by indistinguishable differences due to memory for recollection and familiarity. The parietal old/new effect, a correlate of recollection measured during recognition testing, was only found for experts. The results show that refined perceptual and semantic processing, characteristics of perceptual expertise, facilitate both memory encoding and recognition memory.
\end{abstract}

Keywords ERP P Perceptual expertise $\cdot$ Memory encoding Recognition memory $\cdot \mathrm{Dm} \cdot \mathrm{Old} /$ new effects

\section{Introduction}

Experts are exceptionally skilled in discriminating, learning, and recognizing exemplars of particular categories, like visual objects, tactile patterns, sounds, food, fragrance, or

Electronic supplementary material The online version of this article (doi:10.3758/s13421-010-0036-1) contains supplementary material, which is available to authorized users.

G. Herzmann $(\bowtie) \cdot$ T. Curran

Department of Psychology and Neuroscience,

University of Colorado at Boulder,

UCB 345,

Boulder, CO 80309, USA

e-mail: grit.herzmann@googlemail.com sports. Although improved memory performance is a hallmark of expertise, a systematic investigation of the effects of expertise on neural processing stages of memory encoding and recognition memory is lacking. This study addresses this question by using event-related potentials (ERPs) to determine how perceptual expertise optimizes neural mechanisms of memory encoding and recognition, about which theories of expert memory (Gobet \& Simon, 1996; Rawson \& Van Overschelde, 2008) and behavioral studies have made specific assumptions.

\section{Effects of expertise on perceptual processing}

Previous research has identified several cognitive and neural functions associated with expertise that facilitate perceptual processing. The entry-level shift refers to experts' more automatic and efficient identification of objects at the subordinate level (e.g., Toyota 4Runner) in contrast to novices, who rely predominantly on the basic level (e.g., SUV) for object classification (Bukach, Gauthier, \& Tarr, 2006; Scott, Tanaka, Sheinberg, \& Curran, 2008; Tanaka, 2001; Tanaka \& Taylor, 1991). The entry-level shift is closely connected to the greater ability of experts to discern subtle differences between objects of the same category (i.e. within-category discrimination). Goldstone (1998) identified four mechanisms (attentional weighting, stimulus imprinting, differentiation, and unitization) that underlie perceptual learning and may also support the superior perceptual processing that comes with expertise. Perceptual expertise is associated with better within-category discrimination. Especially two of the four mechanisms are very likely to be enhanced with developing perceptual expertise. Differentiation is the ability to separate initially fused percepts (e.g., categories) from each other, thereby increasing within-category discrimination. Unitization integrates individual parts into single 
functional wholes. Holistic processing, an instance of unitization that further aids within-category discrimination, has been found with increasing levels of expertise (e.g., Bukach et al., 2006). It refers to the tendency of experts to encode information of the entire object as opposed to attending selectively to single parts.

Expertise-related optimization of perceptual processes, which occur very early in information processing and set the foundation for all subsequent processes (Goldstone, 1998), could be one basis for the more accurate memory performance in experts. Expertise could also directly affect the cognitive and neural processes of memory, as suggested by some behavioral studies that focused on the effect of increased semantic knowledge (also called skilled or expert memory) on memory processes. In the following section, we briefly review the major findings and relevant assumptions of these studies.

\section{Effects of expertise on memory processing}

Chess expertise is probably the best-scrutinized field of expertise. Goldin (1979) was one of the first to show a facilitating effect of chess expertise on recognition memory performance and recognition confidence. Earlier studies had demonstrated its effect on free recall in short-term memory tasks (Chase \& Simon, 1973; De Groot, 1966). Better memory performance with higher levels of expertise was found to be caused by higher familiarity with perceptual chess patterns and greater knowledge about these patterns (e.g., labels, strategic moves). Different theories have been put forward to account for the direct relationship of (chess) expertise and superior memory performance. Gobet (1998) reviewed four of these theories and concluded that the template theory (Gobet \& Simon, 1996), which combines assumptions from theories of chunking (Chase \& Simon, 1973) and skilled memory (Chase \& Ericsson, 1982; Ericsson \& Kintsch, 1995), provides the best general account of expertise. These theories propose that superior memory performance results from the interaction of a large database of chunks and a large knowledge base. Experts can more quickly perceive significant patterns (chunks or templates) within complex chess boards. Moreover, encoding and recognition are also facilitated by linking these patterns to semantic knowledge like labels or game actions.

Rawson and Van Overschelde (2008) pointed out the shortcomings of the template theory for expertise with abstract concepts (e.g., National Football League, NFL). Such expertise is based primarily on high levels of semantic knowledge, not on perceptual skills. To accommodate these findings, they developed the distinctiveness theory of skilled memory. This theory extends the template theory by more detailed postulations about the role of semantic knowledge in experts' memory performance. It claims that knowledge promotes memory by improving organizational processing (i.e., generalization of similarities between items in one category) and enhancing distinctive processing of domain-relevant semantic information of single items (i.e., within-category categorization). For the purpose of our study it is important to note the similarities that this theory bears with improved perceptual processing in perceptual expertise: organizational processing is comparable to attentional weighting and categorical perception (Goldstone, 1998); and distinctive processing is similar to withincategory discrimination that relies on stimulus imprinting, differentiation, and unitization (Goldstone, 1998). By transferring the assumptions of theories of expert memory (Gobet \& Simon, 1996; Rawson \& Van Overschelde, 2008) to the realm of perceptual expertise (cars in our study), these theories propose a strong interaction of categorical perception and within-category discrimination, and that superior perceptual skills and increased semantic knowledge lead to improvements in both abilities.

Studies in the field of expert memory and other areas of expertise have added to the evidence of chess research. Some of these studies used episodic memory tasks like remember/ know recognition that made it possible to draw inferences about recollection and familiarity, the two independent processing components thought to underlie recognition memory (Jacoby, 1991; Mandler, 1980; Yonelinas, 2002). Recollection is thought to correspond to the retrieval of specific, meaningful information about a studied item and its encoding context. In contrast, recognition based on familiarity lacks the retrieval of episodic details and arises from identifying a global similarity between a seen item and information stored in memory. Expertise improved overall recognition memory of scholarly terms (Brandt, Cooper, \& Dewhurst, 2005), of words associated with the NFL (Rawson \& Van Overschelde, 2008), and, in hiking experts, of photographs of mountain scenery (Kawamura, Suzuki, \& Morikawa, 2007). Expertise also led to qualitative differences; it facilitated recollection, but not familiarity, for scholarly terms (Brandt, et al., 2005) and Star Trek (Long $\&$ Prat, 2002). These studies of expert memory assumed that recognition processes were improved by the richer and more elaborative encoding of the material that resulted from expertise-based inferences and associations between learned items and existing semantic knowledge. These assumptions coincide with research on level of processing (Craik \& Lockhart, 1972), which shows that access to semantic memory during study enhances how an item is processed. This results in greater probability of recognition and in an even greater probability of recollection; improvements in familiarity have also been observed (e.g., Nyhus \& Curran, 2009; Yonelinas, 2001). 
The so-called other-race effect refers to poorer recognition of other-race than own-race faces. The other-race effect has been attributed to a number of cognitive and social factors (e.g., Meissner \& Brigham, 2001). The contact hypothesis, also known as the experience-based account (Rossion \& Michel, 2010), is of particular relevance to our study. It postulates that humans show expertise-like processing only for faces for which they have superior differential visual experience. In other words, humans are experts for own-race faces and novices for other-race faces. Studies that used episodic memory tasks to investigate the other-race effect yielded similar results as the expertise studies (e.g., Horry, Wright, \& Tredoux, 2010; Marcon, Susa, \& Meissner, 2009; Meissner, Brigham, \& Butz, 2005). Own-race faces were recognized more accurately and relied more on recollection than on familiarity. In addition, lower levels of expertise yielded higher false alarm rates for other-race faces, reflecting poorer discrimination between old and new items.

In sum, findings from studies of perceptual expertise, chess, expert memory, and the other-race effect suggest that the facilitating effect of expertise on memory is caused by fine-tuned perceptual processes like spontaneous subordinate level categorization, holistic processing, and the extraction of salient features that aid within-category discrimination. These perceptual processes are closely linked to broad semantic knowledge about the field of expertise. Learning processes are facilitated by the encoding of only the most salient and highly discriminative features. In addition, expertise-related items are automatically processed in a deeper, semantic fashion during encoding, fostering more detailed and distinct representations in memory. Retrieving representations that combine perceptual and semantic information has thus been found to be easier, more successful, and often accompanied by the conscious recollection of details from the study episode.

\section{Electrophysiological correlates of memory processes}

Despite the broad interest in the superior memory performance of experts, no study has used ERPs to directly investigate alterations in encoding- and recognition-related brain activation that result from expertise. Such an investigation could test the assumptions made by behavioral studies and theories about the effects of expertise on memory encoding and recognition. Three ERP components are of particular interest: the difference due to memory (Dm), the FN400, and the parietal old/new effect. All ERP components are measured as differences between conditions and possess temporal and spatial characteristics consistently found in the literature.

The Dm, which reflects memory encoding in long-term memory, is measured as a posterior positivity between 300 and $1000 \mathrm{~ms}$ in the study phase of a memory task (e.g., Friedman \& Trott, 2000; Paller, Kutas, \& Mayes, 1987; Voss \& Paller, 2009). It is obtained by sorting the ERPs recorded in the study episode according to the participant's memory judgment in the subsequent recognition test. Brain activation in the study phase elicited by faces that are subsequently recognized (i.e., old hits) is more positive over central-parietal regions than that for subsequently forgotten faces (i.e., old misses) (e.g., Duarte, Ranganath, Winward, Hayward, \& Knigth, 2004; Friedman \& Trott, 2000; Voss \& Paller, 2009). Level of processing influences the Dm, but the results are ambiguous; larger Dms can indicate deep, semantic encoding (Gunter, Jackson, \& Mulder, 1992; Paller et al., 1987) or shallow encoding (Schott, Richardson-Klavehn, Heinze, \& Düzel, 2002). Prefrontal, medial-temporal, and parietal areas have been identified as brain regions generating subsequent memory effects in fMRI studies (Spaniol, Davidson, Kim, Han, Moscovitch \& Grady, 2009).

Familiarity and recollection, the two processing components of recognition memory (Jacoby, 1991; Mandler, 1980; Yonelinas, 2002), have each been associated with a characteristic ERP component measured by difference waveforms between successfully recognized old and correctly rejected new items in the test phase. The FN400, found between 300 and $500 \mathrm{~ms}$ as frontal positivity, is thought to reflect processes of familiarity (see Rugg \& Curran, 2007 for a review). It distinguishes hits from correct rejections without being influenced by the recollection of details from the study episode (e.g., Curran, 2000; Curran \& Cleary, 2003; Curran, DeBuse, Woroch, \& Hirshman, 2006; Rugg \& Curran, 2007). An alternate hypothesis sees the FN400 as reflecting conceptional, implicit memory (e.g., Voss \& Paller, 2009; Voss, Schendan, \& Paller, 2010), but there is counter-evidence to this interpretation (Rugg \& Curran, 2007; Stenberg, Hellman, Johansson, \& Rosén, 2009).

The parietal old/new effect reflects recollection processes and is most likely generated in the parietal cortex (see Rugg \& Curran, 2007, for a review). It consists of a parietal positivity between 500 and $800 \mathrm{~ms}$, which varies with the recollection of information from the study episode (Curran, 2000), including source memory (Senkfor \& Van Petten, 1998; Wilding, 2000). Stenberg et al. (2009) provided the first evidence that increased levels of knowledge (i.e., names of celebrities vs. unfamiliar names), which can be taken as similar to expertise, affects the parietal old/new effect but not the FN400. Further evidence for the influence of expertise on the parietal old/new effect comes from a study of the own-age bias, thought to follow similar mechanisms as the other-race effect (Wiese, Schweinberger, \& Hansen, 2008). For young participants, larger old/new effects between 400 and $600 \mathrm{~ms}$ were found for young as compared to old faces. 
Similarly, larger old/new effects (400-600 ms) were found for own- as compared to other-race faces in Caucasian participants (Stahl, Wiese, \& Schweinberger, 2010).

\section{The present study}

Our study aimed to identify the neural processes that underlie superior memory performance in car experts and to link neural mechanisms to behavioral findings and theoretical considerations of expert memory. We measured ERPs indicative of memory encoding and recognition as participants with varying levels of car expertise learned and recognized pictures of cars and birds in a remember $/$ know task. The effect of expertise was determined with multivariate analyses of covariance and correlational analyses. Bird stimuli were included to assess possible influences unrelated to expertise. We expected to find effects of expertise in behavioral and ERP measures for cars. We anticipated higher levels of expertise to be associated with higher levels of accurate memory performance, more correct recollections of old cars, fewer false alarms for new cars, and a more pronounced parietal old/new effect for cars. Previous studies suggested no effect of expertise on familiarity. We therefore did not expect an influence of car expertise on the FN400 for cars. No study so far has measured the influence of expertise on the Dm. Behavioral findings suggested more efficient and spontaneous semantic memory encoding in experts. We thus expected less neural activity to be associated with encoding expertise-related stimuli because research on neural efficiency showed that lower levels of brain activation are associated with more efficient and better performance in a variety of tasks (e.g., Andreasen, O'Leary, Arndt, Cizadlo, Rezai, Watkins, Boles Ponto \& Hichwa, 1995; Babiloni, Marzano, Infarinato, Iacoboni, Rizza, Aschieri, Cibelli, Soricelli, Eusebi \& Del Percio, 2010; Graham, Jiang, Manning, Baladi Nejad, Zhisheng, Salleh, Golay, Berne \& Mc Kenna, 2010; Motes, Malach, \& Kozhevnikov, 2008; Neubauer \& Fing, 2009). Because Dm results for levels of processing are ambiguous, no unequivocal expectations can be formulated for spontaneous semantic encoding (Gunter et al., 1992; Paller et al., 1987; Schott et al., 2002). Effects of expertise on perceptual ERPs were also analyzed and can be found online (mc. psychonomic-journals.org/content/supplemental).

\section{Method}

Participants

Thirty self-reported car experts and 31 car novices with normal or corrected-to-normal visual acuity gave informed consent to participate in the study, approved by the Institutional Review Board of the University of Colorado at Boulder. Participants were recruited by fliers posted around the university campus, addressed to men that were either particularly interested (car experts) or not particular interested (car novices) in cars. Participants received payment of $\$ 15$ per hour for their participation. The novice and expert with the most accurate memory performance each received an additional cash bonus of $\$ 25$. None of the participants was a bird expert as measured with a self-report questionnaire. All subjects were male, aged between 18 and 29 years $(M=21.8$ years, $S D=2.5$ years $)$, and strongly right-handed $(M=79.4, S D=17.0$, range 38-100) according to the Edinburgh Handedness Inventory (Oldfield, 1971). Car expertise, assessed with the subordinate matching task, described below, as a continuous and objective measure did not vary systematically with age or handedness, $F \mathrm{~s}(1,59)=0.4$ and $0.2, p=0.51$ and 0.66 , respectively.

\section{Stimuli and apparatus}

Stimuli for the subordinate matching task were gray scale pictures $\left(256 \times 256\right.$ pixel, $\left.2.9 \times 2.9^{\circ}\right)$ of 168 cars and 168 passerine birds. Stimuli for the recognition experiment were digital, color photographs of 320 cars $(50 \%$ SUVs, $50 \%$ sedans) and 320 birds (50\% owls, 50\% wading birds). All pictures were cropped to show only the car or the bird and were placed on a white background. Car stimuli were 230-256 pixel wide and 90-192 pixel high (visual angle of 2.7-4.8 horizontal by $1.5-3.7^{\circ}$ vertical). Bird stimuli were $90-192$ pixel wide and 90-256 pixel high (visual angle of 1.5-3.7 horizontal by $1.5-4.8^{\circ}$ vertical). Stimuli were shown at a viewing distance of one meter on a 17-inch flat-panel LCD monitor (Apple Studio Display SP110, refresh rate $59 \mathrm{~Hz}$ ). Stimulus presentation (and EEG recording) was time-locked to the refresh point.

\section{Procedure}

The study consisted of two sessions: a behavioral and an EEG session. In the behavioral session, participants completed the subordinate matching task and expertise questionnaires used to measure their level of car and bird expertise. In each questionnaire, participants indicated how many years they had been interested in cars/birds and rated their self-perceived car/bird recognition ability on a scale of 1 to 9 (with 5 corresponding to an average ability and 9 reflecting excellent recognition ability).

The subordinate matching task was conducted in the same way as in previous studies (e.g., Gauthier, Skudlarski, Gore, \& Anderson, 2000). Participants were asked to make same/different judgments about sequentially presented 
images of cars or birds at the level of model or species, respectively. Cars and birds were tested in separate blocks. The category of birds served as baseline for novice-level performance. Each trial started with a fixation cross shown for $200 \mathrm{~ms}$ and replaced by the first stimulus, presented for one second, followed by a mask. After $500 \mathrm{~ms}$ the mask was replaced by the second stimulus, which remained on the screen until the participant made a response or else 5 seconds had passed. Matching stimuli (50\%) were not physically identical but were different exemplars of the same bird species or car model. Participants were asked to press a left key with their left index finger for same trials and a right key with their right index finger for different trials. In the subordinate matching task and in the recognition experiment (described below), the order of stimuli and assignment of response buttons were kept constant for all participants to ensure comparability of task demands. Participants completed a total of 224 trials in eight blocks. The task lasted about 15 minutes.

The EEG session took place one week later and consisted of a priming experiment (not reported here) that always preceded the recognition experiment and included pictures of birds and cars that were from the same species and models, respectively, as the items in the recognition experiment, but no picture was used in both the priming and recognition experiment. In the recognition experiment, eight study blocks alternated immediately with their corresponding recognition blocks. Cars were presented in odd blocks, and birds in even blocks. Forty targets had to be memorized in each study block. In the subsequent recognition block, they had to be discriminated from 40 new, unfamiliar distracters mixed in with the learned targets. Short breaks were allowed within study blocks, between study and recognition blocks, and within recognition blocks to allow the participants to rest their eyes. Longer breaks were allowed before each new study block.

Each trial in the study blocks started with the presentation of a fixation cross for $200 \mathrm{~ms}$, followed by the presentation of a target for two seconds. Inter-stimulus intervals were one second. Participants were instructed to look carefully at the targets and to try to memorize them for the recognition block; no overt response was required. Each trial in the recognition blocks started with the presentation of a fixation cross for $200 \mathrm{~ms}$, followed by a target or a distracter for 1.5 seconds. Participants were asked to withhold their response until the five response options appeared on the screen. This was done to minimize movement-related artifacts. After 1.5 seconds had passed, a horizontal, four-point rating scale and an additional square appeared on the screen below the stimulus. The rating scale consisted of four squares labeled "definitely unfamiliar," "maybe unfamiliar," "maybe familiar," and "definitely familiar." The additional square was labeled "recollect" (following Woodruff, Hayama \& Rugg, 2006). The following response button assignment was used: "recollect"-right index finger, "definitely familiar"-left index finger, "maybe familiar"-left middle finger, "maybe new"-left ring finger, and "definitely new"-left pinky.

Before the experiment, participant received instructions and practice trials for "recollect" and "familiar" memory judgments. They were told to use the "recollect" response if they had a conscious recollection of the prior occurrence of an item in the study phase. Recollection was explained as consciously remembering specific details of the appearance of a face or of the experience learning it: something else that happened in the room, what the participants were thinking or doing, an association that came to mind, or what came just before or after that item in the study phase. In the case that they did not recollect a face, they were asked to rate the familiarity. They were told to use "definitely familiar" or "maybe familiar" if they believed that they had seen the item in the study phase but could not consciously remember anything particular about its appearance or the experience learning it. "Maybe unfamiliar" or "definitely unfamiliar" were to be used if they did not recognize the item from the study phase. Participants were encouraged to make their responses according to their first impression, without time limit. The interval between response and the next fixation cross was one second. One study phase lasted about 2 minutes. One test phase lasted about 15 minutes.

\section{Performance measurement}

The expertise index for cars was computed as the $d^{\prime}$ difference between the car and bird conditions in the subordinate matching task.

For recognition memory performance, we considered percent of hits, percent of false alarms, the area below the receiver operating curve, ROC (P(A); Green \& Swets, 1966), response bias $c_{a}$, and $\mathrm{d}$ ' of "recollect" and "familiar" responses. ROC curves were computed from all five possible response bins, with "recollect" responses treated as reflecting higher confidence than "definitely familiar" responses. Highconfidence correct classifications of distracters (highconfidence correct rejections) and targets (high-confidence "familiar" hits) were used as additional measures of withincategory discrimination ability. High-confidence correct rejections were calculated as the proportion of "definitely new"/(“definitely new"+"maybe new") responses, and highconfidence "familiar" responses as "definitely familiar"/ ("definitely familiar"+"maybe familiar").

Recent research has raised doubts about the extent to which remember/know judgments can be used to estimate separate recollection and familiarity processes rather than merely reflecting confidence differences attributable to a 
single continuously varying memory signal (Dunn, 2004; Rotello, Macmillan, Reeder, \& Wong, 2005; Wixted \& Stretch, 2004). However, because better behavioral dualprocess measures do not exist, we consider them to be a useful adjunct to our ERP indices of familiarity and recollection; but we acknowledge the confidence interpretation of these measures. Raw "recollect" judgments can be interpreted as reflecting recollection from the dual-process perspective, or the highest confidence level from the single process perspective. The raw "familiar" condition comprised memory judgments "maybe familiar" and "definitely familiar", reflect lower levels of confidence from the single process perspective, but cannot be taken as a direct reflection of dual-process familiarity because these responses are contingent on non-recollection. Thus, for the "familiar" condition, we calculated hits and false alarms for the independent remember/know (IRK) estimate of familiarity $(F=K /(1-R)$ where $K$ refers to raw "familiar" responses and $\mathrm{R}$ to raw "recollect" responses (Yonelinas, 2002).

Event-related potential recording and measurement

The EEG was recorded in the study and test blocks with a 128-channel Geodesic Sensor Net ${ }^{\mathrm{TM}}$ (HydroCel GSN 128 1.0, Tucker, 1993; Fig. 1) connected to an AC-coupled, 128-channel, high-input impedance amplifier (200 M $\Omega$, Net
Amps ${ }^{\mathrm{TM}}$, Electrical Geodesics Inc., Eugene, OR). Amplified analog voltages $(0.1-100 \mathrm{~Hz}$ bandpass) were digitized at $250 \mathrm{~Hz}$. The recording reference was the vertex channel $(\mathrm{Cz})$. Individual sensors were adjusted until impedances were less than $50 \mathrm{k} \Omega$.

Epochs of $1100 \mathrm{~ms}$, starting $100 \mathrm{~ms}$ before target onset, were generated offline from the continuous record. Horizontal and vertical eye movements were corrected using the ocular correction ICA transformation in Brain Vision Analyzer 2.0.1 (Brain Products GmbH, Munich, Germany). Trials with non-ocular artifacts were discarded. ERPs were aligned to a 100-ms baseline before target onset, averaged separately for each channel and condition, digitally lowpass filtered at $40 \mathrm{~Hz}$, and recalculated to average reference. A minimum of 15 trials per condition was ensured for each subject $($ mean $=71, \max =123$, for all conditions).

Time segments and regions of interest (ROIs) were defined according to visual inspection (Figs. 2, 3, 4, 5, 6, 7 and 8) and previous research on both the Dm (e.g., Friedman \& Trott, 2000; Paller et al., 1987; Voss \& Paller, 2009) and old/new effects (Curran et al., 2006). Mean amplitudes were computed by averaging the channels within each ROI for each condition and subject. The Dm was divided into two time segments: 300-600 ms and 600-1000 ms. ROIs were centro-medial, parieto-medial, and left and right posterior superior channel groups (CM, PM, LPS, and RPS; Fig. 1).

Fig. 1 Geodesic sensor net layout. Electrode sites are numbered. Black clusters are regions of interest included in analyses. FPo frontal polar, $F R$ frontal right, $L A S$ left anterior superior, $R A S$ right anterior superior, $C M$ centro-medial, $L P S$ left posterior superior, $R P S$ right posterior superior, $P M$ posterior-medial

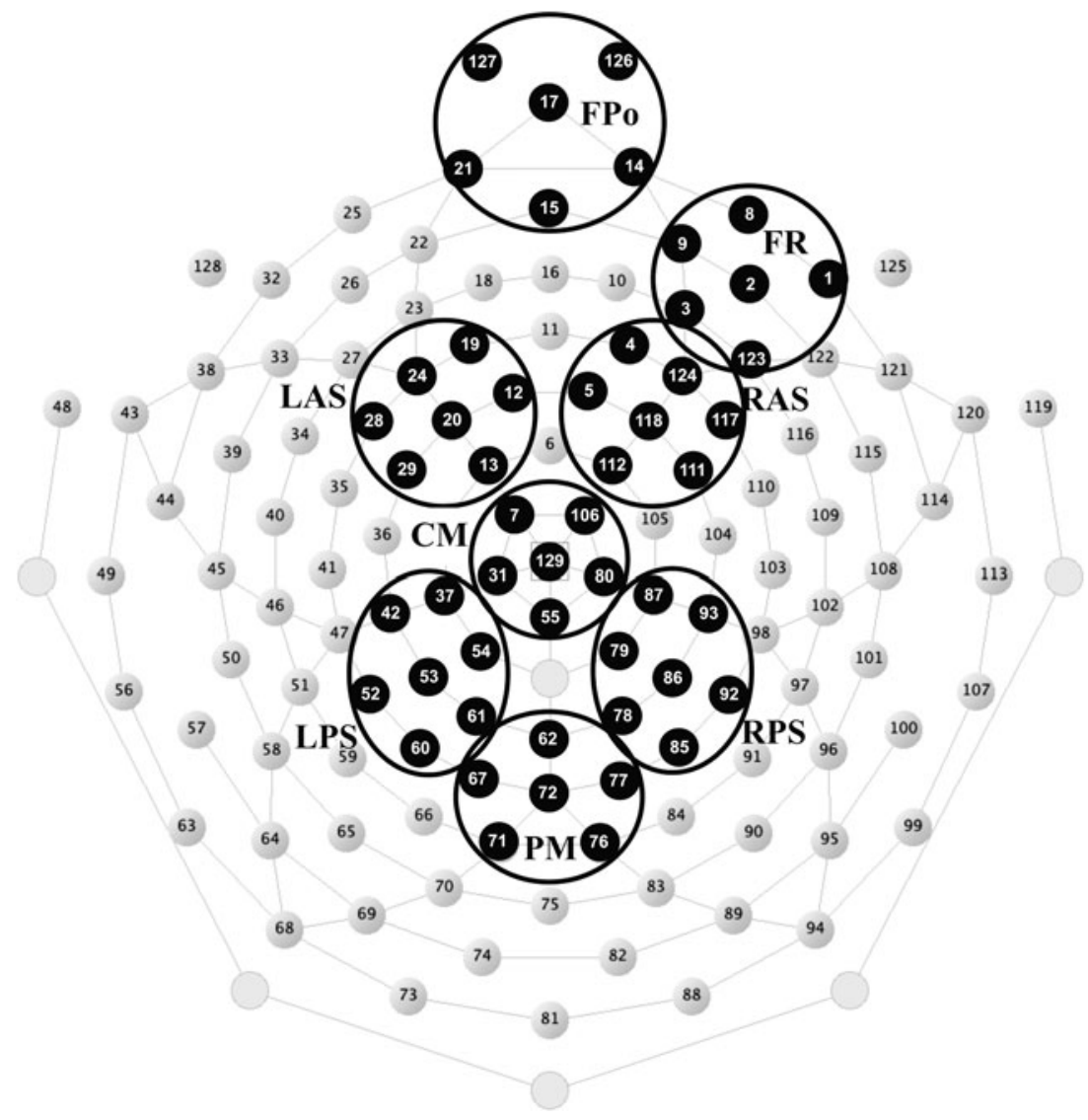



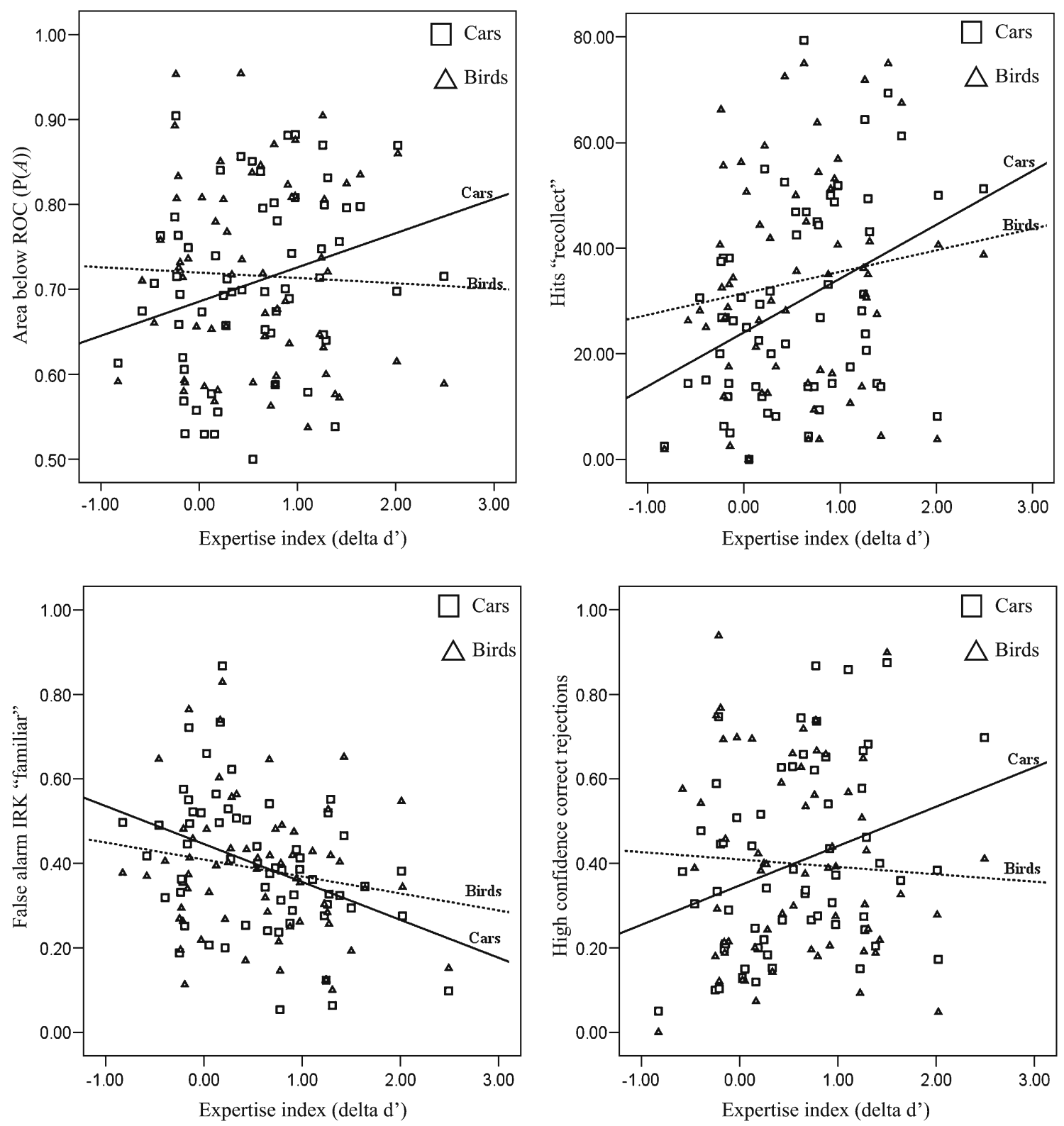

Fig. 2 Scatter plots showing the influence of car expertise as continuous variable. Top left area below the receiver operating curve (ROC), $\mathrm{P}(A)$, regression equation for cars: $\mathrm{Y}=0.04 * \mathrm{X}+0.69, \mathrm{R} 2=$ $0.074, p=0.034 ;$ regression equation for birds: $\mathrm{Y}=-0.06^{*} \mathrm{X}+0.72, \mathrm{R} 2=0.002, p=0.76$ ). Top right hits "recollect", regression equation for cars: $\mathrm{Y}=10.2 * \mathrm{X}+24.0, \mathrm{R} 2=$ $0.15, p=0.002$; regression equation for birds: $\mathrm{Y}=4.1 * \mathrm{X}+31.5$, $\mathrm{R} 2=0.02, p=0.29$. Bottom left false alarms IRK "familiar", regression equation for cars: $\mathrm{Y}=-9.0^{*} \mathrm{X}+42.5, \mathrm{R} 2=0.17, p=$

The FN400 was measured between 300 and $500 \mathrm{~ms}$ and the parietal old/new effect between 500 and $800 \mathrm{~ms}$. ROIs for the FN400 were the centro-medial and left and right anterior superior channel groups (LAS, RAS, and CM; Fig. 1). ROIs for the parietal old/new effect were the centro-medial and left and right posterior superior channel groups (CM, LPS, and RPS; Fig. 1). These ROIs followed studies reported in the

0.001 ; regression equation for birds: $\mathrm{Y}=-4.1 * \mathrm{X}+38.9, \mathrm{R} 2=$ $0.035, p=0.15$. Bottom right high confidence correct rejections, regression equation for cars: $\mathrm{Y}=0.09^{*} \mathrm{X}+0.35, \mathrm{R} 2=0.092, p=$ 0.018 ; regression equation for birds: $\mathrm{Y}=-0.02 * \mathrm{X}+0.41, \mathrm{R} 2=$ $0.003, p=0.68$, for car and bird stimuli. The given regression equations are for the displayed correlations with $\mathrm{Y}$ representing the dependent variable, as displayed in the scatter plot, and $\mathrm{X}$ representing the independent variable, car expertise

literature. To capture expertise effects in regions different from the a priori selected ROIs, two additional ROIs at frontal polar and frontal right regions (FPo and FR; Fig. 1) were defined and included in the analysis of the old/new effects between "familiar" old and correctly rejected new items after visual inspection of topographical maps for car experts and car novices (Fig. 7). 
Cars

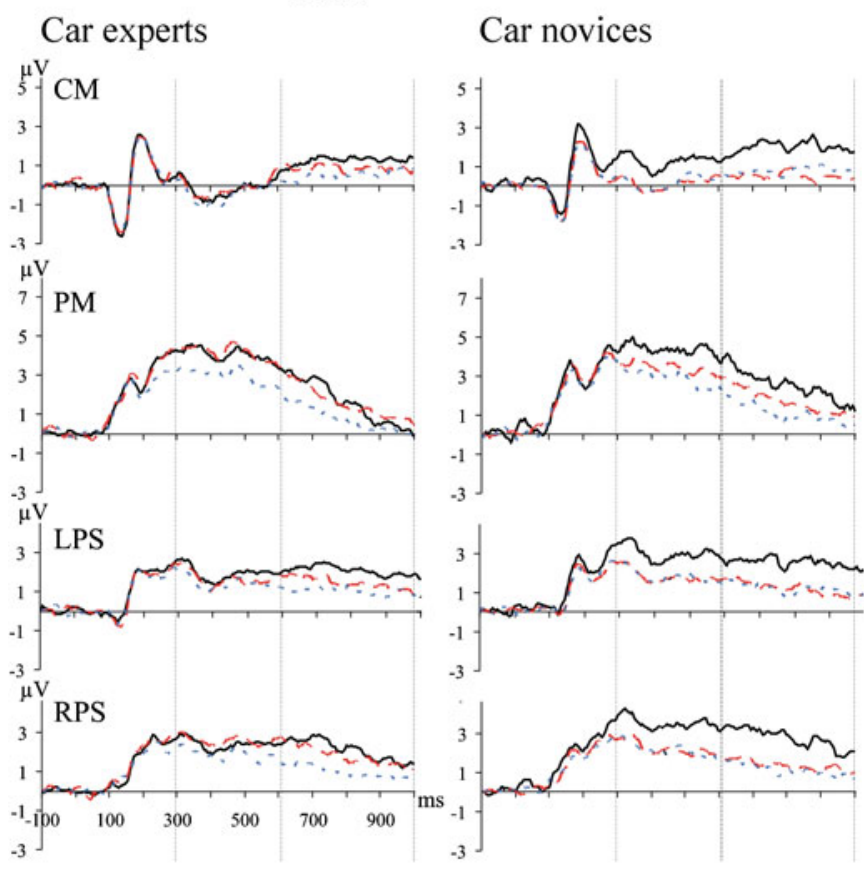

subsequently "recollect"

Fig. 3 Mean amplitudes from the study phase depicting subsequently "recollected," "familiar," and forgotten cars and birds for extreme groups of experts and novices (for illustrative purposes). Vertical lines

\section{Data analysis}

For behavioral and ERP data, we report multivariate analyses of covariance (MANCOVA) with the expertise index as independent variable. In contrast to comparing extreme groups, our approach considers expertise more appropriately as continuous variable. Partial eta-squaredindicating the proportion of the total variability in the dependent variables accounted for by the variation in the independent variable - is provided for all analyses. MANCOVAs were complemented by correlational analyses to further elucidate the expertise effects. For illustrative purposes and in post-hoc tests only (e.g., Table 1 and Figs. 2, 3, 4 and 5), we report data from two extreme groups of car experts and car novices $(N=20$, each) that represent, respectively, the upper and lower ends of the expertise distribution.

\section{Results}

Self-report questionnaires

For cars, higher levels of expertise were associated with more years of self-reported car interest and higher levels of self-rated recognition skills, $F_{\mathrm{S}}(1,59)=22.7$ and $48.4, p=$ $0.0001, \eta_{\text {partial }}^{2}=0.279$ and 0.451 , respectively. Experts
Birds
Car experts

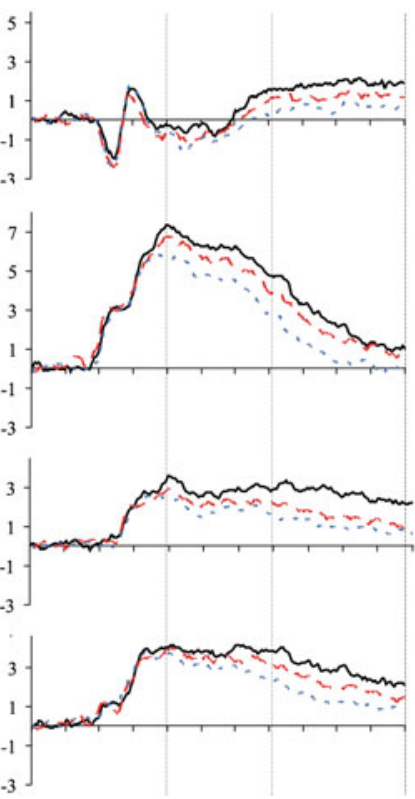

subsequently "familiar"
Car novices

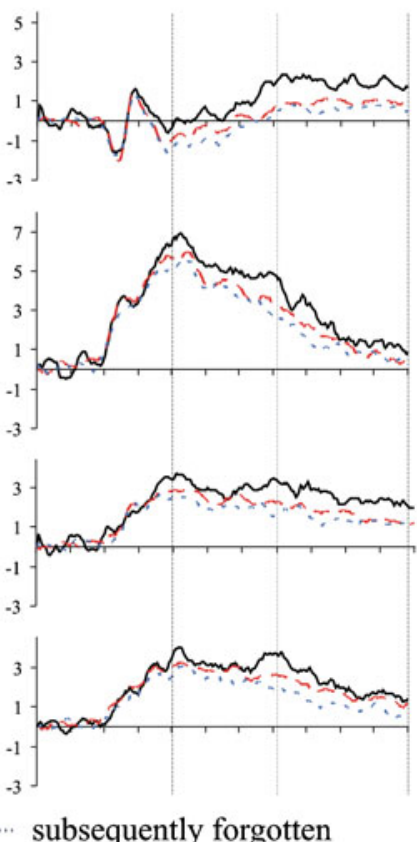

highlight the time segments $300-600 \mathrm{~ms}$ and $600-1000 \mathrm{~ms}$, which were used for statistical analyses. See Fig. 1 for abbreviations of regions of interest and their locations

and novices were not interested in birds and indicated 0 years of bird interest. Expertise did not systematically vary with self-reported bird recognition skills, $F(1,59)=$ $0.06, p=0.81, \eta_{\text {partial }}^{2}=0.001$.

\section{Recognition memory performance}

Table 1 illustrates behavioral indicators of memory performance and summarizes statistical parameters (i.e., significance level and partial eta squared derived from the MANCOVAs, and Pearson $r$ correlation) for the influence of car expertise (measured as continuous variable by the expertise index) on all behavioral indicators of memory performance.

\section{Covariations with expertise}

Effects of expertise were analyzed by MANCOVAs including the factor category (cars, birds) and the expertise index as independent variable. Percent of hits and false alarms for raw "familiar" judgments are given in Table 1 for informative purposes. Statistical analysis, however, was confined to the IRK familiarity, which is independent from recollection and thus more meaningful in the context of differences in "recollect" judgments (Yonelinas, 2002).

Significant expertise $\mathrm{x}$ category interactions were found in the area below the ROC curve $(\mathrm{P}(A)), F(1,59)=$ 
Fig. 4 Illustration of the influence of car expertise on the mean amplitude of subsequently "recollected" cars and birds in the study phase of the experiment. Shown are mean ERP amplitudes (top) and their topographies (middle) for extreme groups of car experts and car novices (for illustrative purposes) as well as a scatter plot depicting the correlations between car expertise and the mean ERP amplitude for cars and birds (bottom; regression equation for cars:

$\mathrm{Y}=-0.80 * \mathrm{X}+2.76, \mathrm{R} 2=$ $0.089, p=0.019$; regression equation for birds:

$\mathrm{Y}=-0.26 * \mathrm{X}+3.03, \mathrm{R} 2=$ $0.009, p=0.46)$. Spherical spline interpolation was used for voltage maps
Mean ERP amplitude for subsequently "recollected" stimuli at LPS
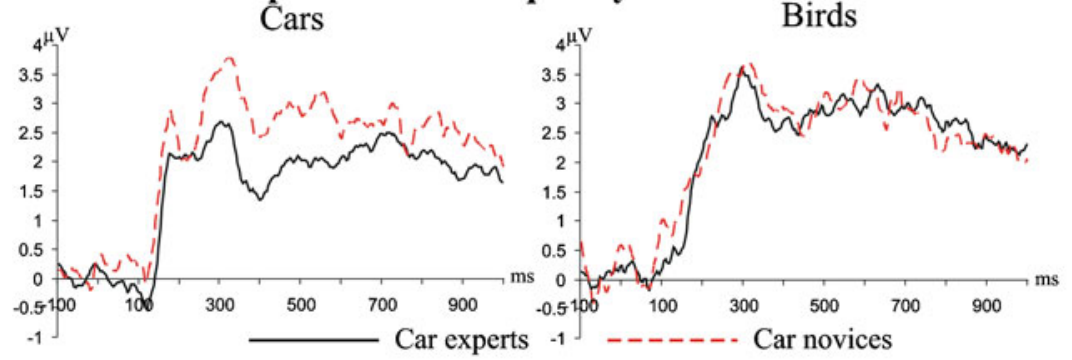

Topographies of mean amplitudes for subsequently "recollect" stimuli

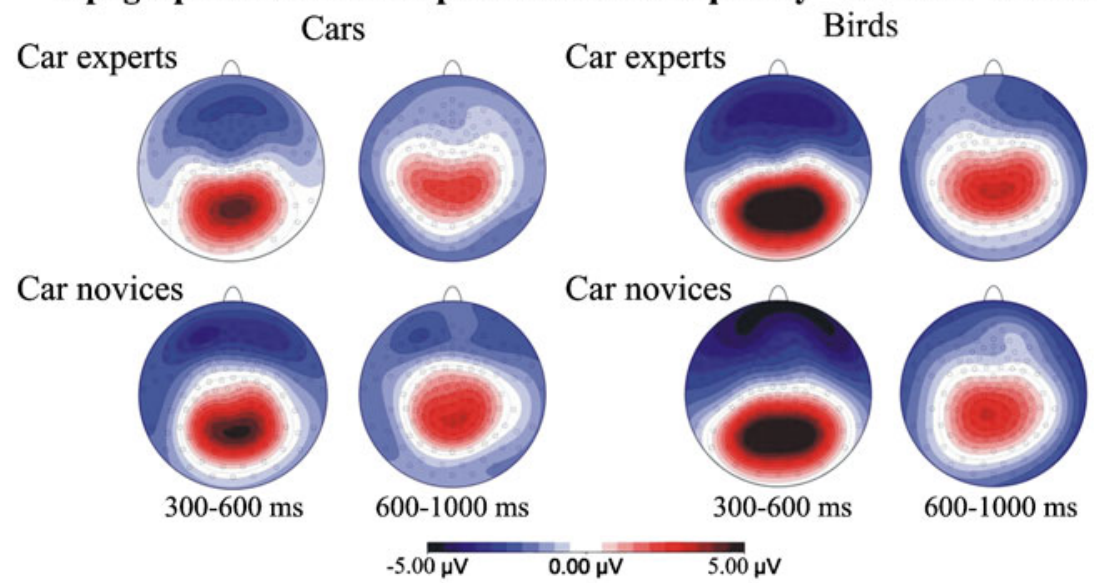

Scatter plot of correlation between expertise index and mean ERP amplitude of subsequently "recollected" stimuli at LPS (300-600 ms)

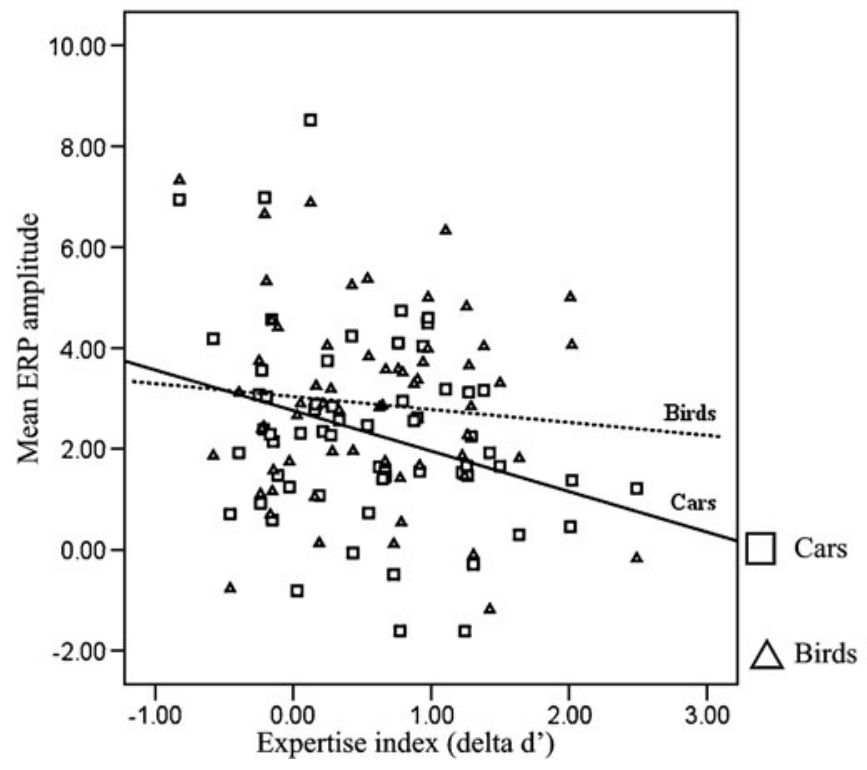

20.1, $p=0.0001$; the percent of hits for "recollect" judgments, $F(1,59)=13.9, p=0.0001$; the percent of high confidence "familiar" hits, $F(1,59)=7.0, p=0.01$; the percent of high confidence correct rejections, $F(1,59)=25.4$, $p=0.0001$; the percent of false alarms for IRK familiarity, $F(1,59)=7.9, p=0.007$; the d' for "recollect" judgments, $F(1,59)=7.1, p=0.01$; and the d' for IRK familiarity, $F(1,59)=7.9, p=0.007$.
Expertise did not influence the response bias $\mathrm{c}_{\mathrm{a}}, p=0.28$, IRK familiarity, $p=0.96$, or the percent of false alarms for "recollect" judgments, $p=0.78$.

Considering cars and birds separately, expertise enhanced performance only for cars. Expertise significantly improved overall recognition performance with cars, $F(1,59)=4.7, p=$ 0.034 , enhanced high confidence correct rejections, $F(1,59)=$ $6.0, p=0.018$, reduced false alarms for IRK familiarity to 
Fig. 5 Illustration of the influence of car expertise on the Dm between subsequently "recollected" and "familiar" cars and birds in the study phase of the experiment. Shown are mean amplitudes of ERP difference waves (top) and their topographies (middle) for extreme groups of car experts and car novices (for illustrative purposes) as well as a scatter plot depicting the correlations between car expertise and the mean amplitude of ERP difference waves for cars and birds (bottom; regression equation for cars: $\mathrm{Y}=-0.63 * \mathrm{X}+0.79$, $\mathrm{R} 2=0.082, p=0.025$; regression equation for birds: $\mathrm{Y}=0.03 * \mathrm{X}+0.25$,

$\mathrm{R} 2=0.000, p=0.92)$. Spherical spline interpolation was used for voltage maps
ERPs of difference waves subsequently "recollect" minus "familiar" at RPS

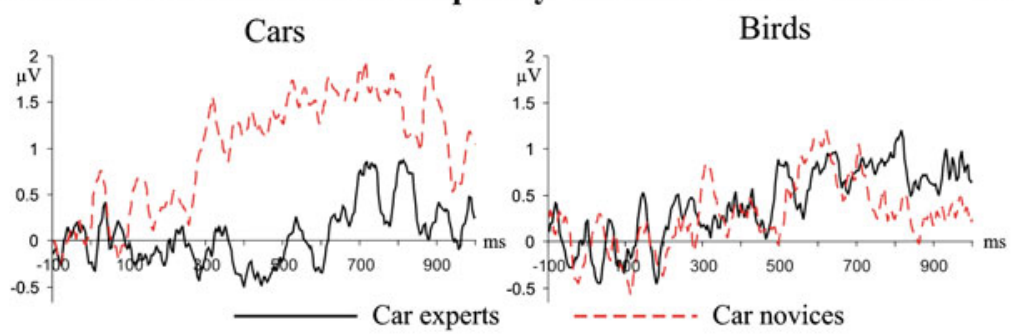

Topographies of difference waves subsequently "recollect" minus "familiar" Car experts
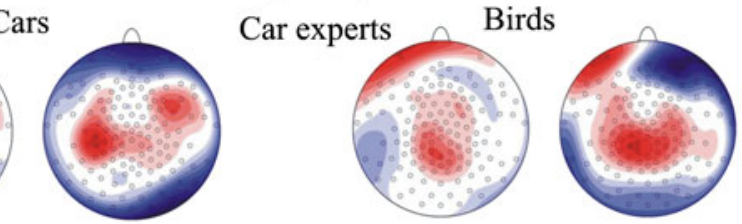

Car novices
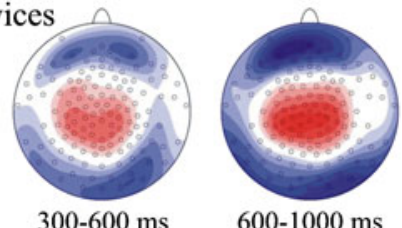

Car novices
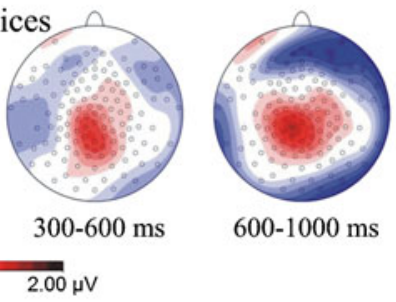

600-1000 ms

$600-1000 \mathrm{~ms}$

Scatter plot of correlation between expertise index and ERPs of difference waves subsequently "recollect" minus "familiar" at RPS (600-1000 ms)

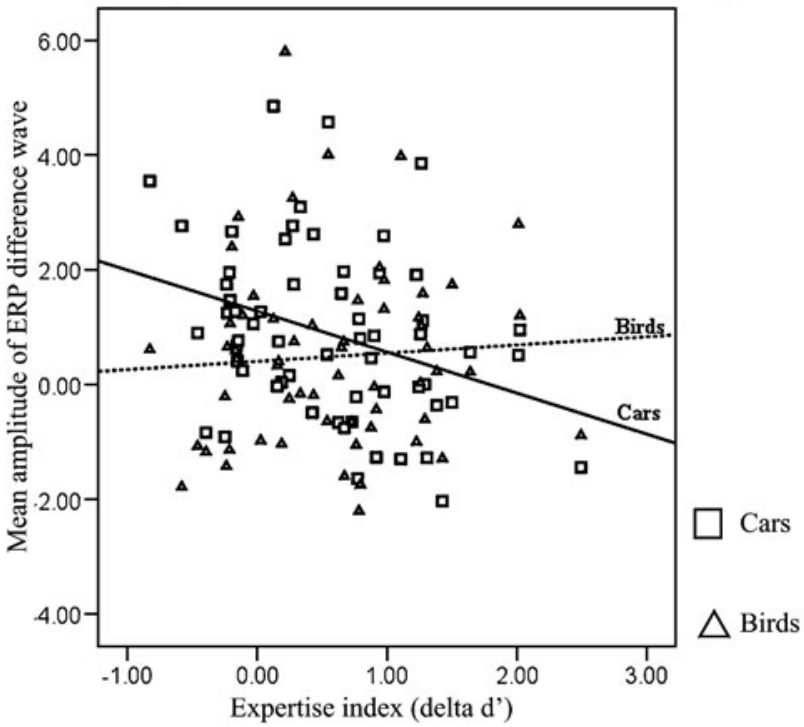

new cars, $F(1,59)=10.8, p=0.002$, and led to more, correct "recollect" judgments for old cars, $F(1,59)=10.3, p=0.002$. Post-tests for high confidence "familiar" hits, the d' of "recollect" judgments, and the d' of IRK familiarity for cars were not significant, $p=0.14,0.37$, and 0.42 , respectively. For birds, car expertise did not affect overall recognition, $p=$ 0.76 , "recollect" hits, $p=0.29$, high confidence "familiar" hits, $p=0.46$, high confidence correct rejections, $p=0.68$, percent of false alarms for IRK familiarity, $p=0.18$, d' for "recollect" judgments, $p=0.51$, or the d' for IRK familiarity, $p=0.23$. All d' measures for cars and birds were significantly different from chance, $t(60)>10.3, p<0.001$.

For correlational results see Table 1 and Fig. 2. Figure 2 shows the expertise-specific correlations.

Difference due to memory (Dm) during encoding

Average waveforms from the study phase are illustrated for extreme groups of experts and novices in Fig. 3. Mean amplitudes are largest for subsequently "recollected" items, 


\section{Cars}

\section{Car experts} $\mu \mathrm{V}_{\mathrm{FPo}}$
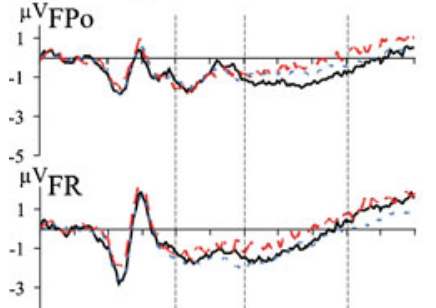

${ }_{\mu \mathrm{V}}^{5}$ LAS

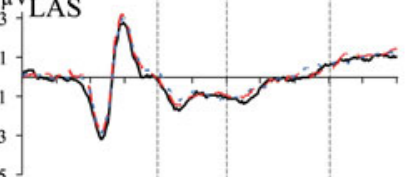

RAS

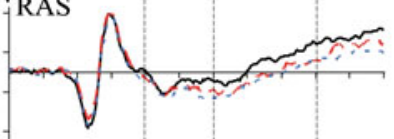

$\mathrm{V}$

$5-\mathrm{CM}$

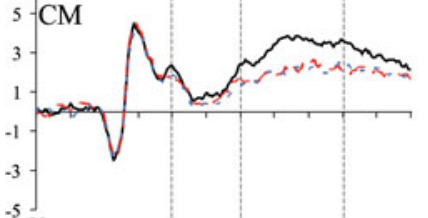

LPS

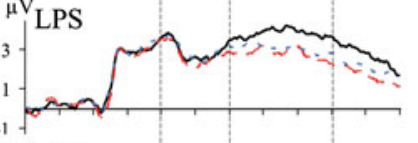

$\mu \mathrm{V}_{\mathrm{RPS}}$

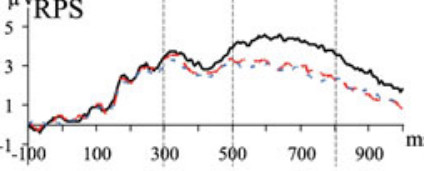

"recollect"
Car novices
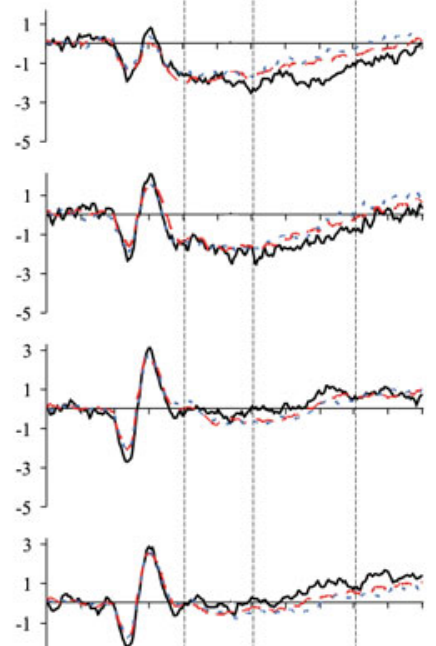

$-1$
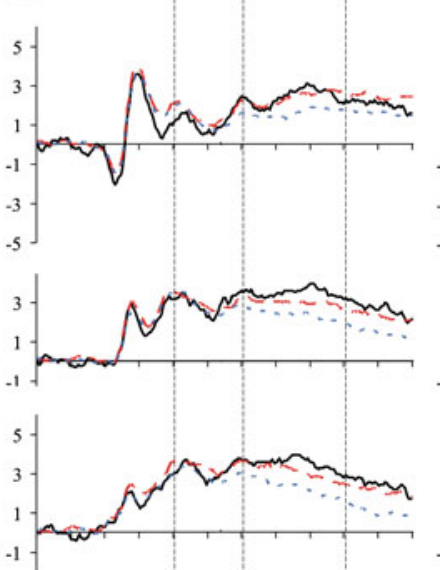

- - - - - - -

Fig. 6 Mean amplitudes from the test phase depicting "recollected" and "familiar" old cars and birds and correctly rejected new cars and birds for extreme groups of experts and novices (for illustrative

intermediate for subsequently "familiar" items, and smallest for subsequently forgotten items (Fig. 3). The existence of significant Dms was confirmed by a repeated-measures analysis of variance (ANOVA) including the factors time segment (300-600 ms, 600-1000 ms), category (cars, birds), subsequent memory judgment ("recollect," "familiar," forgotten), and ROI (CM, PM, LPS, RPS). The significant main effect of subsequent memory judgment, $F(2,120)=$ 23.1, $p=0.0001$, indicated significant differences between brain activations accompanying the three subsequent memory judgments and thus significant Dms. The interaction time segment $\mathrm{x}$ subsequent memory judgment, $F(2,120)=7.1, p=0.002$, showed that Dms between 600 and $1000 \mathrm{~ms}$ were larger than those between 300 and $600 \mathrm{~ms}$ (Fig. 3). Dms did not differ between cars and birds, $p=0.94$.

\section{Birds}

Car experts
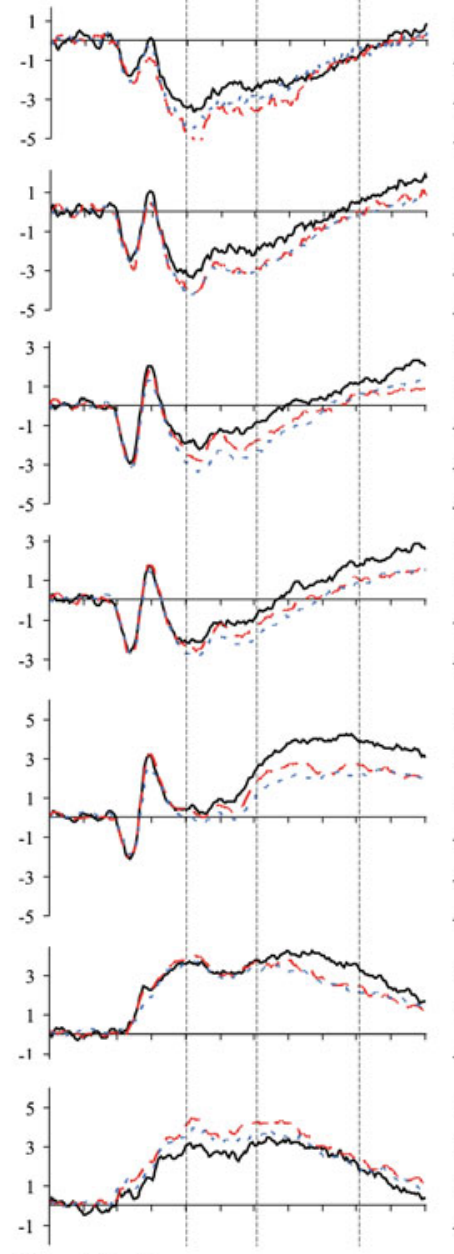

"familiar"

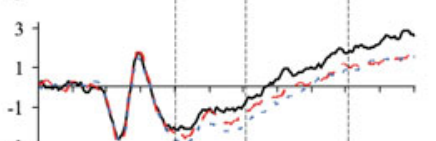

Car novices

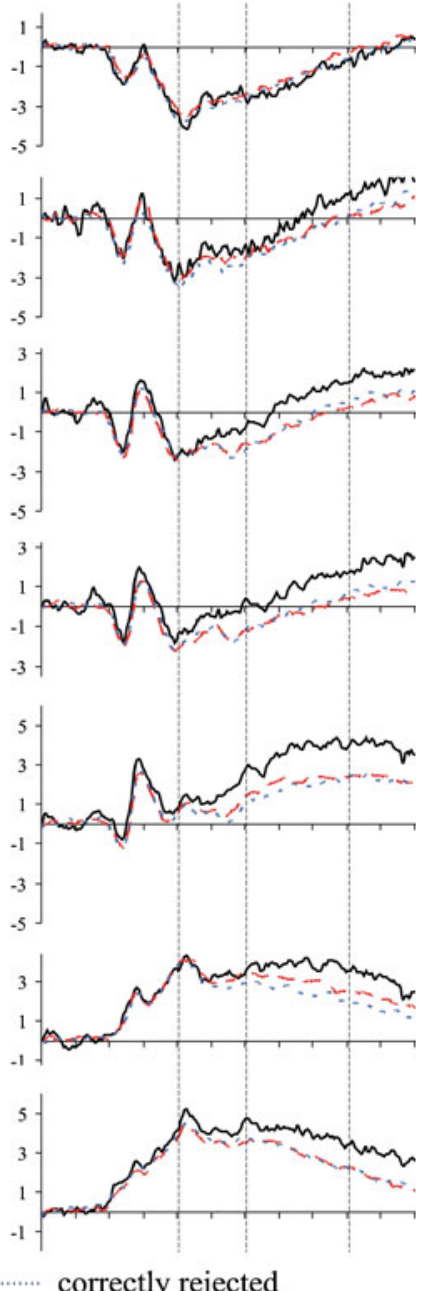

correctly rejected purposes). Vertical lines highlight the time segments 300-500 ms and 500-800 ms, which were used for statistical analyses. See Fig. 1 for abbreviations of regions of interest and their locations

\section{Covariations with expertise}

Effects of expertise were analyzed with repeated-measures MANCOVAs, for the following factors: time segment (300-600 ms, 600-1000 ms), category (cars, birds), and ROI, as well as the expertise index as independent variable, for each mean amplitude of subsequent memory judgment (i.e., "recollect", "familiar", forgotten) and each Dm (i.e., difference waves between subsequently "recollected" minus subsequently "familiar;" subsequently "recollected" minus subsequently forgotten; subsequently "familiar" minus subsequently forgotten). To investigate expertise effects further, we also conducted repeated-measures MANCOVAs separately for cars and birds.

Effects of expertise were most apparent for cars, especially in the mean amplitude for "recollected" cars, 
Fig. 7 Illustration of the influence of car expertise on the old/ new effect between "familiar" and correctly rejected cars and birds in the test phase of the experiment. Shown are mean amplitudes of ERP difference waves (top) and their topographies (middle) for extreme groups of car experts and car novices (for illustrative purposes) as well as a scatter plot depicting the correlations between car expertise and the mean amplitude of ERP difference waves for cars and birds (for FR at bottom left, regression equation for cars: $\mathrm{Y}=0.70 * \mathrm{X}+-0.06$, $\mathrm{R} 2=0.073, p=0.036$; regression equation for birds: $\mathrm{Y}=-0.03 * \mathrm{X}+0.05$, $\mathrm{R} 2=0.000, p=0.92$; for LPS at bottom right, regression equation for cars:

$\mathrm{Y}=-0.51 * \mathrm{X}+0.20$,

$\mathrm{R} 2=0.13, p=0.005$; regression equation for birds:

$\mathrm{Y}=-0.20 * \mathrm{X}+0.58$,

$\mathrm{R} 2=0.012, p=0.41$. Spherical spline interpolation was used for voltage maps
ERPs of difference waves "familiar" minus correct rejection at FR and LPS

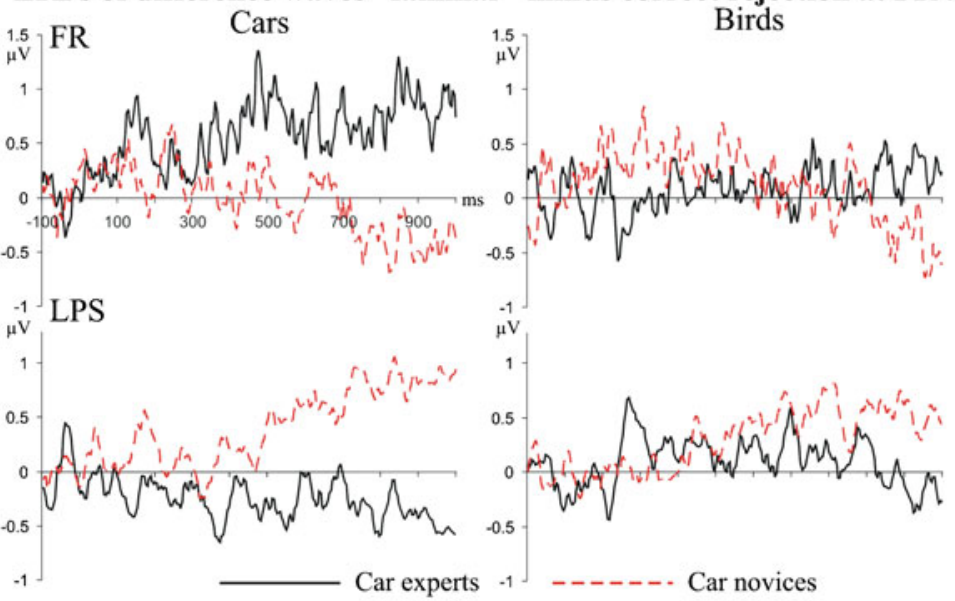

Topographies of difference waves "familiar" minus correct rejection

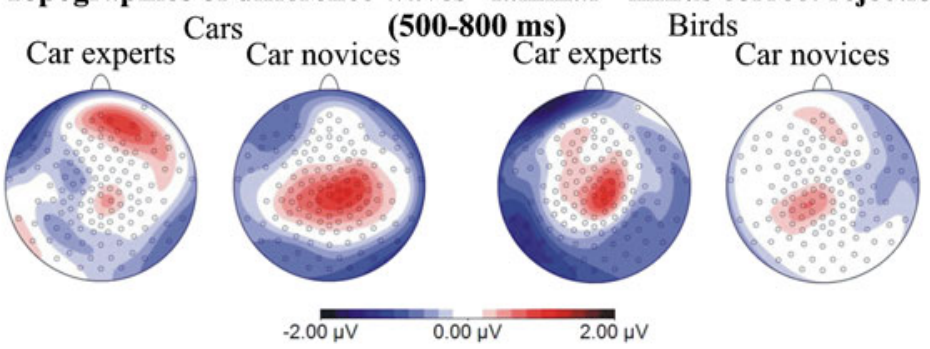

Scatter plot of correlation between expertise index and ERPs of difference waves "familiar" minus correct rejection at FR and LPS (500-800 ms)
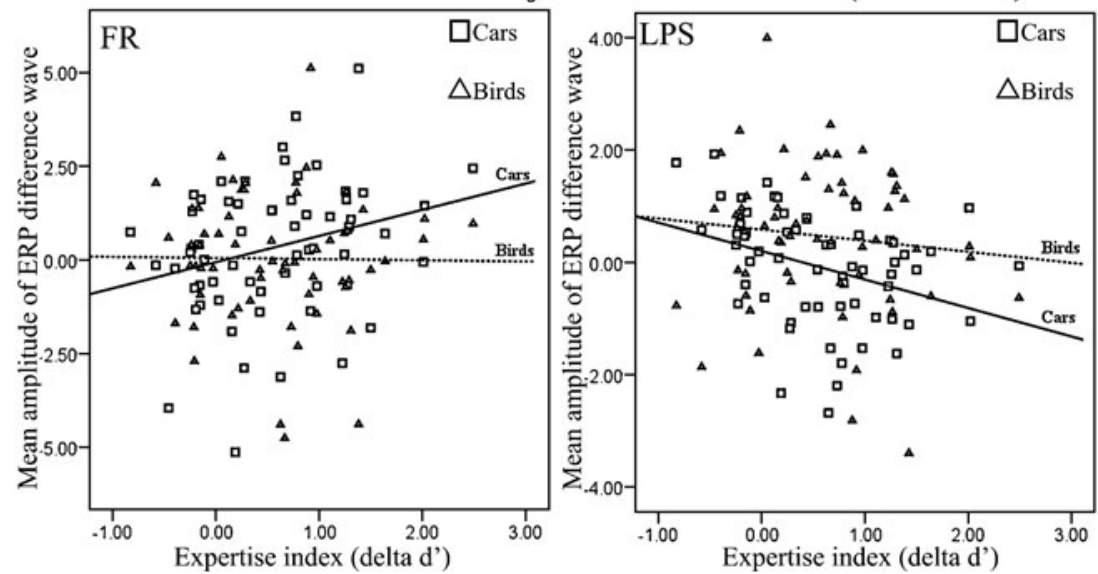

which was smaller for participants with higher levels of expertise than for those with lower levels of car expertise (Figs. 3 and 4). This observation was confirmed by a significant interaction expertise index x category, $F(1,59)=$ $4.5, p=0.037, \eta_{\text {partial }}^{2}=0.071$. Car expertise significantly influenced the mean amplitude of subsequently "recollected" cars, $F(1,59)=6.0, p=0.018, \eta_{\text {partial }}^{2}=0.092$, but not for birds, $p=0.671, \eta_{\text {partial }}^{2}=0.003$. Figure 4 illustrates this effect. Higher levels of car expertise led to less positive amplitudes for cars at CM, LPS, and RPS, Fs
$(1,59)=6.1,4.4$, and 4.5, $p=0.016,0.039$, and 0.037, $\eta_{\text {partial }}^{2}=0.095,0.070$, and 0.072 , respectively. Research on neural efficiency showed that lower brain activation can be associated with higher mental abilities and superior task performance (e.g., Andreasen et al., 1995; Babiloni et al., 2010; Graham et al., 2010; Motes et al., 2008; Neubauer \& Fing, 2009). Less positive amplitudes for subsequently "recollected" cars thus may indicate more efficient memory encoding for participants with higher levels of car expertise. No other effect of car expertise was 
Fig. 8 Illustration of the influence of car expertise on the old/ new effect between "recollected" and "familiar" cars and birds in the test phase of the experiment. Shown are mean amplitudes of ERP difference waves (top) and their topographies (middle) for extreme groups of car experts and car novices (for illustrative purposes) as well as a scatter plot depicting the correlations between car expertise and the mean amplitude of ERP difference waves for cars and birds (bottom; regression equation for cars: $\mathrm{Y}=0.63^{*} \mathrm{X}+0.67$, $\mathrm{R} 2=0.065, p=0.049$; regression equation for birds: $\mathrm{Y}=-0.11 * \mathrm{X}+1.36$, $\mathrm{R} 2=0.001, p=0.84)$. Spherical spline interpolation was used for voltage maps
ERPs of difference waves "recollect" minus "familiar" at CM Cars

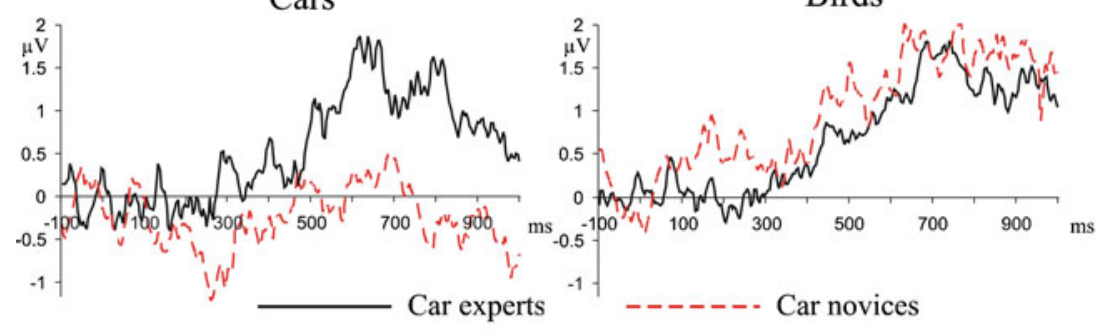

Topographies of difference waves "recollect" minus "familiar"

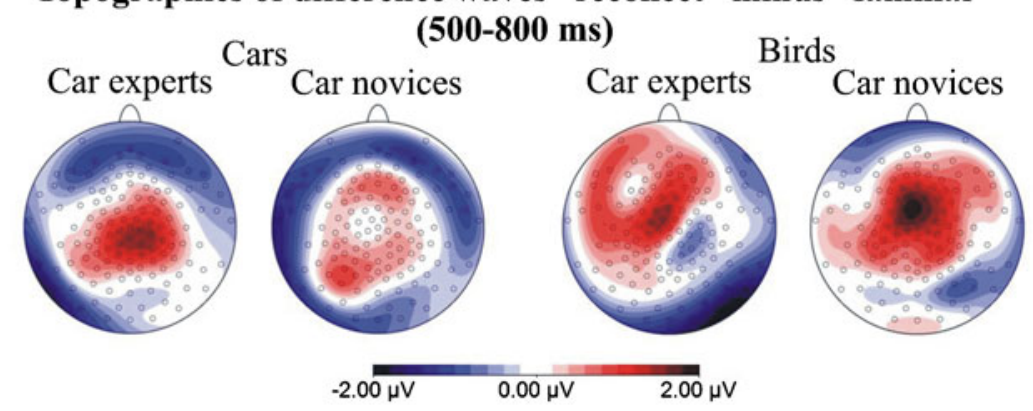

Scatter plot of correlation between expertise index and ERPs of difference waves "recollect" minus "familiar" at CM (500-800 ms)

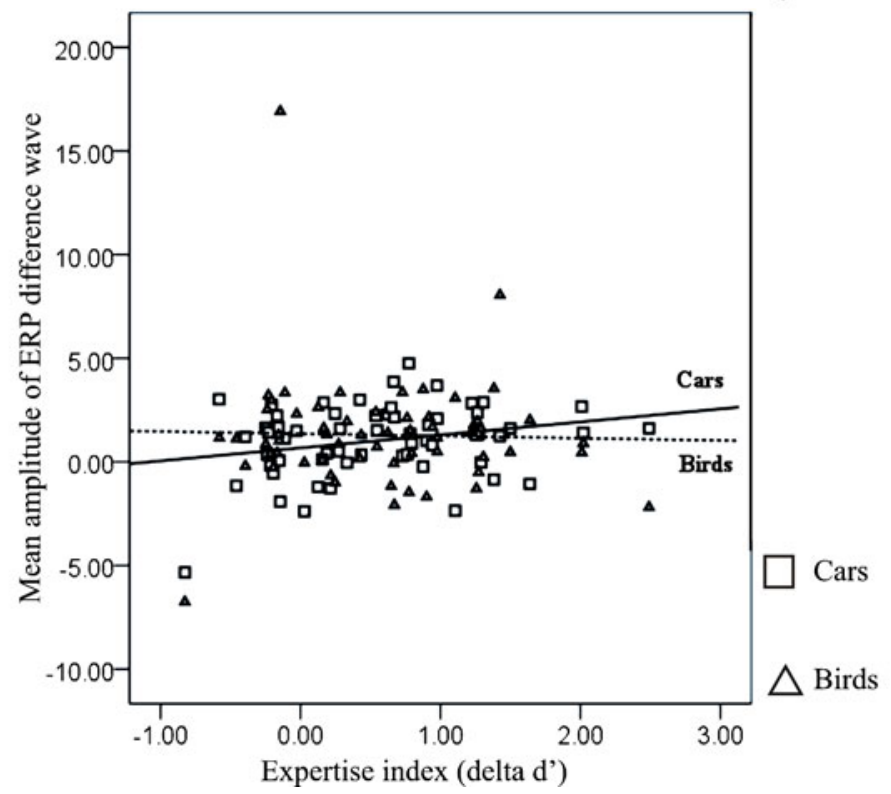

found for any other mean amplitude of subsequent memory judgment, ruling out possible influences of generally higher brain activity.

Effects of expertise seemed also present in the Dm between "recollected" and "familiar" cars; it was smaller for participants with higher levels of expertise than for those with lower levels of car expertise (Figs. 3 and 5). For the Dm between subsequently "recollected" and "familiar" stimuli, a trend for a significant interaction expertise index $\mathrm{x}$ category, $F(1,59)=3.3, p=0.071, \eta_{\text {partial }}^{2}=0.053$, emerged. Car expertise significantly influenced this Dm for cars, $F(1,59)=6.3, p=0.015, \eta_{\text {partial }}^{2}=0.096$, but not for birds, $p=0.741, \eta_{\text {partial }}^{2}=0.002$. Figure 5 illustrates this effect. Higher levels of car expertise were associated with a smaller Dm for cars at CM, LPS, RPS, and PM, $F_{\mathrm{s}}(1,59)=$ $3.3,3.7,7.2$, and 3.6, $p=0.07,0.05,0.01$, and 0.06 , $\eta_{\text {partial }}^{2}=0.054,0.060,0.109$, and 0.058 , respectively. This finding suggests that for car experts similar encoding processes led to subsequent familiarity and recollection with car stimuli. In contrast, subsequent familiarity and 
Table 1 Illustration of the memory performance for extreme groups of car experts and car novices and statistical indicators (significance at level $p<0.05$ and $\eta_{\text {partial }}^{2}$ from MANCOVAs, Pearson $\mathrm{r}$ correlation and the $95 \%$ confidence interval around the correlation) for the influence of car expertise, measured as a continuous variable by the expertise index, on behavioral memory performance. Measures for raw "familiar" responses were not included in the statistical analyses

\begin{tabular}{|c|c|c|c|c|c|c|c|c|c|c|c|c|}
\hline \multirow{3}{*}{$\begin{array}{l}\text { Behavioral indicator } \\
\text { of recognition } \\
\text { performance }\end{array}$} & \multicolumn{6}{|l|}{ Cars } & \multicolumn{6}{|l|}{ Birds } \\
\hline & \multicolumn{2}{|c|}{$\begin{array}{l}\text { Performance for } \\
\text { extreme groups }\end{array}$} & \multicolumn{4}{|c|}{ Influence of expertise index } & \multicolumn{2}{|c|}{$\begin{array}{l}\text { Performance for } \\
\text { extreme groups }\end{array}$} & \multicolumn{4}{|c|}{ Influence of expertise index } \\
\hline & $\begin{array}{l}\text { Car } \\
\text { experts }\end{array}$ & $\begin{array}{l}\text { Car } \\
\text { novices }\end{array}$ & $p$ & $\eta_{p}^{2}$ & $r$ & $\begin{array}{l}\text { Confidence } \\
\text { interval for } \\
r\end{array}$ & $\begin{array}{l}\text { Car } \\
\text { experts }\end{array}$ & $\begin{array}{l}\text { Car } \\
\text { novices }\end{array}$ & $p$ & $\eta_{p}^{2}$ & $r$ & $\begin{array}{l}\text { Confidence } \\
\text { interval for } \\
r\end{array}$ \\
\hline $\mathrm{P}(A)$ & 0.75 & 0.67 & yes & 0.074 & $0.27 *$ & $\begin{array}{c}0.02 \text { to } \\
0.49\end{array}$ & 0.72 & 0.71 & no & 0.002 & -0.04 & $\begin{array}{c}-0.29 \text { to } \\
0.22\end{array}$ \\
\hline $\mathrm{c}_{\mathrm{a}}$ & -0.12 & -0.21 & no & 0.042 & 0.20 & $\begin{array}{c}-0.05 \text { to } \\
0.43\end{array}$ & -0.15 & -0.20 & no & 0.002 & 0.14 & $\begin{array}{c}-0.12 \text { to } \\
0.38\end{array}$ \\
\hline Hits "recollect" & 0.38 & 0.20 & yes & 0.149 & $0.39 * *$ & $\begin{array}{c}0.15 \text { to } \\
0.59\end{array}$ & 0.37 & 0.29 & no & 0.019 & 0.13 & $\begin{array}{c}-0.13 \text { to } \\
0.38\end{array}$ \\
\hline Hits IRK “familiar" & 0.54 & 0.60 & no & 0.084 & $-0.29 *$ & $\begin{array}{c}-0.51 \text { to } \\
-0.04\end{array}$ & 0.53 & 0.60 & no & 0.083 & - & $0.29 *$ \\
\hline \multicolumn{13}{|l|}{-0.51 to -0.04} \\
\hline Hits raw "familiar" & 0.33 & 0.47 & - & - & - & - & 0.33 & 0.41 & - & - & - & - \\
\hline $\begin{array}{l}\text { High confidence } \\
\text { "familiar" hits }\end{array}$ & 0.51 & 0.41 & no & 0.036 & 0.19 & $\begin{array}{c}-0.07 \text { to } \\
0.43\end{array}$ & 0.44 & 0.46 & no & 0.011 & -0.10 & $\begin{array}{c}-0.35 \text { to } \\
0.16\end{array}$ \\
\hline $\begin{array}{l}\text { High confidence } \\
\text { correct rejections }\end{array}$ & .45 & .32 & yes & 0.092 & $0.30 *$ & $\begin{array}{c}0.05 \text { to } \\
0.52\end{array}$ & 0.35 & 0.41 & no & 0.003 & -0.05 & $\begin{array}{c}-0.31 \text { to } \\
0.21\end{array}$ \\
\hline $\begin{array}{l}\text { False alarm } \\
\text { "recollect" }\end{array}$ & 0.05 & 0.04 & no & 0.020 & 0.14 & $\begin{array}{c}-0.12 \text { to } \\
0.38\end{array}$ & 0.06 & 0.05 & no & 0.033 & 0.18 & $\begin{array}{c}-0.08 \text { to } \\
0.42\end{array}$ \\
\hline $\begin{array}{l}\text { False alarm IRK } \\
\text { "familiar" }\end{array}$ & 0.33 & 0.45 & yes & 0.154 & $-0.39 * *$ & $\begin{array}{c}-0.15 \text { to } \\
-0.59\end{array}$ & 0.35 & 0.39 & no & 0.031 & 0.18 & $\begin{array}{c}-0.42 \text { to } \\
0.08\end{array}$ \\
\hline $\begin{array}{l}\text { False alarm raw } \\
\text { "familiar" }\end{array}$ & 0.31 & 0.43 & - & - & - & - & 0.33 & 0.37 & - & - & - & - \\
\hline d' "recollect" & 1.62 & 1.33 & no & 0.013 & 0.12 & $\begin{array}{c}-0.14 \text { to } \\
0.37\end{array}$ & 1.39 & 1.42 & no & 0.007 & -0.09 & $\begin{array}{c}-0.34 \text { to } \\
0.17\end{array}$ \\
\hline d' IRK “familiar" & 0.58 & 0.42 & no & 0.011 & 0.11 & $\begin{array}{c}-0.15 \text { to } \\
0.36\end{array}$ & 0.49 & 0.58 & no & 0.025 & -0.16 & $\begin{array}{c}-0.40 \text { to } \\
0.10\end{array}$ \\
\hline
\end{tabular}

$P(A)$ area below the receiver operating curve, $c_{a}$ response bias, IRK independent remember/know, $p$ significance at level $p<0.05, \eta_{p}^{2}$ partial eta squared (same as R2), $r$ Pearson $r$ correlations

recollection differed during study for participants with low levels of car expertise and for all participants when encoding birds (Figs. 3 and 5).

Table 2 summarizes the correlational results that further elucidate the influence of car expertise as continuous variable on ERP components of memory encoding. In summary, the $\mathrm{Dm}$ in response to cars correlated with several behavioral measures of expert performance, whereas the Dm to birds did not.

Old/new effects during recognition

Average waveforms of old/new effects from the test phase of the recognition experiment are illustrated for the extreme groups of experts and novices in Fig. 6. Mean amplitudes are largest for "recollected", intermediate for "familiar", and smallest for correctly rejected new items. The existence of significant old/new effects was investigated with a repeatedmeasures ANOVA including the factors category (cars, birds), memory judgment ("recollect," "familiar," correct rejection), and ROI. For the FN400 (300-500 ms), the significant main effect of memory judgment, $F(2,120)=6.2$, $p=0.005$, indicated significant differences between brain activations accompanying the three memory judgments. The FN400 did not differ between cars and birds, $p=0.110$. The same results were found when including five ROIs. For parietal old/new effects $(500-800 \mathrm{~ms})$, the significant main effect of memory judgment, $F(2,120)=26.7, p=0.0001$, 
Table 2 Pearson $r$ correlations between behavioral indicators of expertise and the difference due to memory in the $300-600 \mathrm{~ms}$ and $600-1000 \mathrm{~ms}$ time intervals. See Fig. 1 for abbreviations of regions of interest and their location

\begin{tabular}{|c|c|c|c|}
\hline Behavioral indicator & ERP indicator & $\begin{array}{l}\text { Correlations with } \\
\text { ERPs for cars }\end{array}$ & $\begin{array}{l}\text { Correlations with } \\
\text { ERPs for birds }\end{array}$ \\
\hline \multicolumn{4}{|c|}{ Time segment between 300 and $600 \mathrm{~ms}$} \\
\hline \multirow[t]{2}{*}{$\begin{array}{l}\text { Expertise index } \\
\text { (delta d') }\end{array}$} & $\begin{array}{l}\text { Mean amplitude cars "recollect" } \\
\text { at CM, LPS, RPS }\end{array}$ & $\begin{array}{l}-0.37^{* *},-0.31^{*} \\
\quad-0.26^{*}\end{array}$ & $-0.19,-0.10,0.05$ \\
\hline & $\begin{array}{l}\text { Dm "recollect" minus "familiar" } \\
\text { at RPS }\end{array}$ & $-0.29 *$ & 0.01 \\
\hline Hits "recollect" cars & $\begin{array}{l}\text { Mean amplitude cars "recollect" } \\
\text { at CM }\end{array}$ & $-0.26^{*}$ & -0.14 \\
\hline \multirow[t]{2}{*}{$\begin{array}{l}\text { False alarm IRK } \\
\text { "familiar" }\end{array}$} & $\begin{array}{l}\text { Mean amplitude cars "recollect" } \\
\text { at CM, RPS }\end{array}$ & $0.34 * *, 0.25 *$ & $0.10,-0.03$ \\
\hline & $\begin{array}{l}\text { Dm "recollect" minus "familiar" } \\
\text { at RPS }\end{array}$ & $0.31^{*}$ & -0.09 \\
\hline \multicolumn{4}{|c|}{ Time segment between 600 and $1000 \mathrm{~ms}$} \\
\hline \multirow[t]{2}{*}{$\begin{array}{l}\text { Expertise index } \\
\text { (delta d') }\end{array}$} & $\begin{array}{l}\text { Mean amplitude cars "recollect" } \\
\text { at RPS, PM }\end{array}$ & $-0.24 *,-0.24 *$ & $0.06,0.01$ \\
\hline & $\begin{array}{l}\text { Dm "recollect" minus "familiar" } \\
\text { at CM, RPS, PM }\end{array}$ & $\begin{array}{l}-0.24^{*},-0.33^{* *} \\
-0.26^{*}\end{array}$ & $-0.20,0.07,0.03$ \\
\hline \multirow[t]{2}{*}{$\begin{array}{l}\text { High confidence } \\
\text { correct rejections }\end{array}$} & $\begin{array}{l}\text { Mean amplitude cars "recollect" } \\
\text { at CM, LPS }\end{array}$ & $-0.36^{* *},-0.24^{*}$ & $-0.21,-0.07$ \\
\hline & $\begin{array}{l}\text { Dm "recollect" minus "familiar" } \\
\text { at CM, LPS, RPS }\end{array}$ & $\begin{array}{l}-0.27 *,-0.34 * * \\
\quad-0.31\end{array}$ & $-0.07,-0.09,0.04$ \\
\hline \multirow[t]{2}{*}{$\begin{array}{l}\text { False alarm IRK } \\
\text { "familiar" }\end{array}$} & $\begin{array}{l}\text { Mean amplitude cars "recollect" } \\
\text { at CM, RPS }\end{array}$ & $0.25^{*}, 0.24^{*}$ & $0.04,-0.09$ \\
\hline & $\begin{array}{l}\text { Dm "recollect" minus "familiar" } \\
\text { at RPS }\end{array}$ & $0.30^{*}$ & -0.14 \\
\hline
\end{tabular}

IRK independent remember/

know

"recollect" implies subsequently recollected; "familiar" implies subsequently judged as

"familiar"; forgotten implies subsequently forgotten

$* p<0.05 ; * * p<0.01$ with lower car expertise levels and larger over frontal-right regions for participants with higher car expertise levels. This observation was confirmed by a significant interaction expertise index $\mathrm{x}$ category $\mathrm{x}$ ROI, with ROI including $\mathrm{CM}$, LPS, RPS, FPo, and FR, $F(4,240)=2.9, p=0.025$, $\eta_{\text {partial }}^{2}=0.046$. Car expertise significantly influenced the old/new effect between "familiar" and correctly rejected cars, interaction expertise index x ROI, $F(3,240)=5.2$, $p=0.001, \eta_{\text {partial }}^{2}=0.080$, but not for birds, $p=0.59$, $\eta_{\text {partial }}^{2}=0.012$. For higher levels of car expertise, the "familiar" vs. new memory difference was larger at FR, $F$ $(1,59)=4.6, p=0.036, \eta_{\text {partial }}^{2}=0.073$, and smaller at LPS, $F(1,59)=8.5, p=0.005, \eta_{\text {partial }}^{2}=0.126$. Figure 7 illustrates this effect. This finding shows that different levels of expertise are associated with different retrieval strategies, because right-frontal ERP old/new effects have been associated with retrieval monitoring (e.g., Cruse \& Wilding, 2009; Friedman \& Johnson, 2000; Hayama, Johnson, \& Rugg, 2008).

The parietal old/new effect between "recollected" and "familiar" old cars (Fig. 6) appeared to be larger for car experts than for car novices. When including the traditional three ROIs, the MANCOVA for the memory difference between "recollected" and "familiar" stimuli did not show an interaction expertise index $\mathrm{x}$ category, $F(1,59)=1.7, p=0.198, \eta_{\text {partial }}^{2}=0.028$. When tested for cars and birds separately car expertise tended to influenced the memory difference between "recollected" and "familiar" cars, 
$F(1,59)=3.2, p=0.078, \eta_{\text {partial }}^{2}=0.053$, but not for birds, $p=0.679, \eta_{\text {partial }}^{2}=0.003$. Higher levels of car expertise were associated with a more positive "recollect" vs. "familiar" memory difference for cars at CM, $F(1,59)=$ $4.1, p=0.047, \eta_{\text {partial }}^{2}=0.065$. In post-hoc tests, only experts showed a significant memory difference between "recollected" and "familiar. Figure 8 illustrates this effect. ${ }^{1}$ Because the old/new effect between "recollected" and "familiar" items has been related to recollection (Rugg \& Curran, 2007), this finding suggests that participants with high levels of car expertise retrieved more episodic details together with the recognized car and engaged relevant memory networks to a greater extent.

Table 3 summarizes the correlational results that further elucidate the influence of car expertise as continuous variable on ERP components of recognition. Again, correlations were seen for old/new effects of cars but not of birds. Correlations thus provided additional evidence for the expertise-specific influence of car expertise on ERP old/ new effects for cars. Although significant parietal old/new effects were found for bird stimuli (similar to those seen in car experts with cars; Fig. 6), they did not correlate with the expertise index. Instead, it could be argued that birds elicited larger parietal old/new effects because they are easier to learn, which was confirmed by, overall, more accurate recollections of birds than cars ("recollect" hits: 0.34 for birds, 0.29 for cars, $t(60)=3.2, p<0.01$ ).

\section{Discussion}

The results of this study showed that expertise affected memory encoding and recognition as measured by behavioral performance and ERP components. We will discuss these findings in turn.

\section{Behavioral memory performance}

Participants with higher levels of car expertise (i.e., car experts) recognized cars more accurately and "recollected" old cars more often than participants with lower levels of expertise (i.e., car novices), ${ }^{2}$ as observed frequently in

\footnotetext{
${ }^{1}$ When excluding outliers (ERP activation greater $\pm 2.5 \mathrm{SD}$, i.e., $-7 /$ $+8 \mu \mathrm{V})$ seen in Fig. 8 from the correlational analysis, the correlation between expertise index and ERP old/new effect is reduced slightly for cars (from 0.26 to 0.23 ) and increased slightly for birds (from 0.03 to 0.03$)$.

${ }^{2}$ To simplify the Discussion, we will refer to participants with higher levels of car expertise as (car) experts and to participants with lower levels of car expertise as (car) novices. Although this phrasing could give the impression that extreme group analyses were performed, we want to emphasize that car expertise was investigated as a continuous variable.
}

previous research (Brandt et al., 2005; Goldin, 1979; Kawamura et al., 2007; Long \& Prat, 2002; Rawson \& Van Overschelde, 2008). Effect sizes of the expertise effects in our study were small to medium, replicating previously reported effect sizes in memory performance for experts and novices (Horry et al., 2010; Long \& Prat, 2002; Marcon et al., 2009). We found expertise effects consistently in measures of recollection ("recollect" hits and d'). In addition, expertise reduced familiarity-related false alarms for new items. It is very likely that the homogeneity of the present stimuli material caused this effect. Stimuli consisted of multiple exemplars from similar models of cars (and species of birds). Only expertise-related objects are differentiated on the subordinate level (e.g., Toyota 4 Runner or barn owl), whereas differentiation of other objects usually occurs on the basic level (e.g., SUV or owl). Under these circumstances cars were very similar for novices - thereby making discrimination difficult and increasing false alarm rates as typically observed for similar lures (Curran, 2000; Curran \& Cleary, 2003; Hintzman \& Curran, 1994; Roediger \& McDermott, 1995) and for otherrace faces (e.g., Horry et al., 2010; Meissner \& Brigham, 2001).

The behavioral results show that expertise facilitates recollection processes and also increased the ability to discriminate successfully between old and new objects. Deeper encoding of the most distinctive features, which facilitate within-category recognition, has been suggested to underlie this expertise-specific memory performance (Gobet \& Simon, 1996; Goldstone, 1998; Rawson \& Van Overschelde, 2008). These assumptions are supported by our correlational results (Table 1). More successful recollection, more high confidence correct rejections, and reduced false alarms were associated with higher levels of subordinate level categorization ability, a marker of refined perceptual processing. The effect of car expertise on memory performance with cars cannot be attributed to overall higher memory ability, motivation, or attention, because no influence of car expertise was seen for memory performance with birds.

From a single-process perspective, the "recollection" advantage associated with expertise could be interpreted as a confidence effect, which would also provide a parsimonious account of the confidence effects observed for correct rejections. However, parietal old/new effects provide converging evidence for the different influence that expertise has on recollection, as discussed later.

\section{ERP encoding effects}

Expertise had two effects on memory encoding. It led to less positive amplitudes for subsequently "recollected" cars and similar brain activation for subsequent recollection and 
Table 3 Pearson $r$ correlations between behavioral indicators of expertise and the parietal old/ new effect between 500 and 800 ms. See Fig. 1 for abbreviations of regions of interest and their location

ONE old/new effect, IRK independent remember/know $* p<.05 ; * * p<.01$

\begin{tabular}{|c|c|c|c|}
\hline Behavioral indicator & ERP indicator & $\begin{array}{l}\text { Correlations with } \\
\text { ERPs for cars }\end{array}$ & $\begin{array}{l}\text { Correlations with } \\
\text { ERPs for birds }\end{array}$ \\
\hline \multirow[t]{2}{*}{$\begin{array}{l}\text { Expertise index } \\
\text { (delta d') }\end{array}$} & $\begin{array}{l}\text { ONE cars "recollect" minus } \\
\text { "familiar" at CM }\end{array}$ & $0.26^{*}$ & -0.03 \\
\hline & $\begin{array}{l}\text { ONE cars "familiar" minus correct } \\
\text { rejection at FR, LPS }\end{array}$ & $0.27^{*},-0.36^{*}$ & $-0.01,-0.11$ \\
\hline \multirow[t]{2}{*}{$\mathrm{P}(A)$} & $\begin{array}{l}\text { Mean amplitude cars "recollect" at } \\
\text { CM, RPS }\end{array}$ & $0.25^{*}, 0.26^{*}$ & $-0.06,0.02$ \\
\hline & $\begin{array}{l}\text { ONE cars "recollect" minus } \\
\text { "familiar" at CM }\end{array}$ & $0.25^{*}$ & -0.20 \\
\hline Hits "recollect" cars & $\begin{array}{l}\text { ONE cars "familiar" minus correct } \\
\text { rejection at } \mathrm{CM}\end{array}$ & $-0.34 * *$ & 0.03 \\
\hline $\begin{array}{l}\text { High confidence } \\
\text { correct rejections }\end{array}$ & $\begin{array}{l}\text { ONE cars "familiar" minus correct } \\
\text { rejection at FPo, CM, RPS }\end{array}$ & $\begin{array}{l}0.26^{*},-0.28^{*} \\
-0.36^{* *}\end{array}$ & $-0.15,0.02,-0.04$ \\
\hline $\begin{array}{l}\text { False alarm IRK } \\
\text { "familiar" }\end{array}$ & $\begin{array}{l}\text { ONE cars "familiar" minus correctly } \\
\text { rejected at FPo, FR }\end{array}$ & $-0.38 * *,-0.34 * *$ & $0.22,-0.04$ \\
\hline
\end{tabular}

familiarity. It is still not entirely clear what operations are involved in the encoding processes that differentiate later recollection from later familiarity. Previous Dm research (e.g., Duarte et al., 2004; Friedman \& Trott, 2000; Voss \& Paller, 2009) typically found clear differences between subsequent recollection and familiarity, as was also found here for novices and for all subjects with bird stimuli. Only two studies reported no ERP differences between subsequent recollection and familiarity. Smith (1993) required his participants to engage in deep encoding by thinking about the meaning of each word. This led to similar brain activation for subsequently recognized items, whether "familiar" or "recollected." Friedman and Trott (2000) reported similar activation for "recollect" and "familiar" words in older but not in younger subjects. Because older subjects showed less accurate recognition performance, it was assumed that they generally encoded items to the same, shallow level, which led to indistinguishable brain activations. Both findings suggest that similar encoding processes - either deep or shallow-led to indistinguishable Dms for subsequent recollection and familiarity. Given the superior memory performance of car experts in our study, similarly deep encoding of subsequently "recollected" and "familiar" cars in the study phase is a likely explanation for the present Dm results in car experts. In light of the assumptions made in expert memory about the interaction of perceptual processing and semantic knowledge theories (Gobet \& Simon, 1996; Rawson \& Van Overschelde, 2008), and considering the significant correlations of the Dm in our study with superior subordinate level categorization (Table 2), deep perceptual processing or an interaction of deep perceptual and deep semantic processing could also have caused indistinguishable Dms for subsequent recollection and familiarity.

Less positive amplitudes in experts can be interpreted as reflecting neural efficiency (e.g., Andreasen et al., 1995; Babiloni et al., 2010; Graham et al., 2010; Motes et al.,
2008; Neubauer \& Fing, 2009). One fMRI study reported less encoding-related activation for subjects with high rather than low memory ability (Heinze, Sartory, Müller, de Greiff, Forsting \& Jüptner, 2006). No study has tested the effects of expertise or different levels of mental abilities on the Dm, but our results are consistent with the view that experts who had higher memory ability for cars than novices, showed lower Dm amplitudes because they encoded cars more efficiently.

Studies of expert memory have assumed that the facilitating effect of expertise on memory is caused by fine-tuned perceptual processes that closely interact with broad semantic and conceptual knowledge (e.g., Brandt et al., 2005; Kawamura et al., 2007; Long \& Prat, 2002) and theories (Gobet \& Simon, 1996; Rawson \& Van Overschelde, 2008). They suggested that encoding processes are accomplished in an automatically deeper, semantic fashion. Encoding was also assumed to be parsimonious, because extensive expertise-related knowledge aids the encoding of only the most discriminative features for within-category recognition. The results of our study provide neural evidence for these assumptions in the form of correlations (Table 2) between fine-tuned perceptual processing (subordinate-level categorization and withincategory discrimination) and encoding-related ERPs. Experts showed similar Dms for subsequent recollection and familiarity that might indicate an interaction of superior perceptual and semantic memory encoding. Successful memory encoding for subsequent recollection in experts was supported by more efficient and better organized activation of encoding-related networks as seen in lower amplitudes for later "recollected" cars.

ERP retrieval effects

Influences of expertise on old/new effects were weaker than on ERP components of memory encoding attenuating strong 
inferences about expertise effects on recognition processes. No influence of car expertise was seen for the FN400, replicating the behavioral findings that also showed no effect of expertise on measures of familiarity apart from the false alarm rate. For the parietal old/new effect, significantly different brain activations between "recollected" and "familiar" memory judgments for cars were found only for car experts, whereas all subjects showed this old/new effect for bird stimuli (Figs. 6 and 8). Although the statistical evidence for this finding is weak (e.g., the expertise x stimulus category interaction was not significant, although parietal amplitudes at CM correlated with expertise for cars but not birds), it coincides with results of previous studies on increased knowledge (Stenberg et al., 2009), on the own-age bias (Wiese et al., 2008), and the other-race effect (Stahl et al., 2010).

We previously noted that the behavioral results could be interpreted as expertise, enhancing confidence rather than recollection per se. However, previous research has suggested that parietal old/new effects vary between "recollect" and "familiar" responses without varying with level of familiarity confidence (Woodruff et al., 2006). The finding in our study for the parietal old/new effects suggests that recollection, not just confidence, increases with expertise.

Correlations showed that perceptual expertise was also associated with higher mean amplitudes for "recollected" cars (Table 3). More positive amplitudes to "recollected" items and larger parietal old/new effects were also found in studies on levels of processing for items in the deep, semantic encoding condition (e.g., Curran, 2000; Paller, Kutas, \& McIsaac, 1995; Rugg, Mark, Walla, Schloerscheid, Birch \& Allan, 1998). A recent study, however, showed that perceptual factors, in addition to semantic factors, can affect the parietal old/new effect (Nyhus \& Curran, 2009). Thus, expertise-related modulations of the parietal old/new effect might originate from increased perceptual and semantic processing, as seen in superior subordinate-level classification, better memory recognition performance, and deeper as well as more parsimonious memory encoding as indicated by the Dm. Results from the parietal old/new effect add to the behavioral and Dm findings. Together, these findings provide evidence for theoretical assumptions of expert memory theories (Gobet \& Simon, 1996; Rawson \& Van Overschelde, 2008) by showing that details from the study episode are more likely to be consciously recollected for expertise-related stimuli because of refined perceptual and semantic processing during initial learning.

Car expertise significantly modulated the distribution of old/new effects between "familiar" and correctly rejected cars, but not for birds. During recognition, perceptual expertise led to an increased involvement of right anterior brain regions, whose engagement was correlated with lower false alarms, more confident correct rejections, and better subordinate-level categorization. Right-frontal ERP old/ new effects have been associated with retrieval monitoring (e.g., Cruse \& Wilding, 2009; Friedman \& Johnson, 2000; Hayama et al., 2008). One retrieval strategy is the distinctiveness heuristic (also called diagnostic monitoring), which refers to the meta-cognition of "If I had seen this item at study, I would remember it." (Schacter, Israel, \& Racine, 1999). Engaging in this strategy led to a pattern of results very similar to our findings in car experts: reduced false alarms, more confident correct rejections, and rightfrontal old/new effects seen in ERPs (Budson, Droller, Dodson, Schacter, Rugg, Holcomb \& Daffner, 2005) and fMRI (Gallo, McDonough, \& Scimea, 2009). Expertise thus changes the recognition strategy, making it more likely to use a distinctiveness heuristic that leads to superior within-category discrimination.

Expertise effects on recognition memory vs. free recallTheoretical reflections

The majority of expertise studies used free recall, which is typically more difficult than recognition, and might thus be a better measure for superior memory performance. A recognition task does not require the encoding of all features of a stimulus to successfully discriminate targets and distracters, whereas free recall demands more complete information to reconstruct the encoded stimulus (Goldin, 1979; McGregor \& Howes, 2002). This aspect of recognition tasks is particularly important for expertise research. First, in order to effectively discriminate targets from very similar distracters, the most salient and distinct features have to be encoded during study. Only experts possess this ability as indicated by better subordinate categorization ability and lower false alarm rates. They are thus more likely not only to encode quantitatively more representations, but also to create qualitatively different -more distinct and detailed-representations that emphasize those features that facilitate within-category discrimination (Brandt et al., 2005; Goldstone, 1998). Our results confirm this assumption. Experts did not only recognize more cars, they also made more correct "recollect" judgments and fewer false alarms. Brain activations in the study and test phases showed correlations to this quantitatively and qualitatively superior memory performance (Tables 2 and 3).

Second, because a recognition task does not require the encoding of all features of a given stimulus, resources are available for operations of semantic memory during encoding. The influence of semantic memory can thus become more evident in a recognition task (McGregor \& Howes, 2002). Similar brain activation for subsequent recollection and familiarity for experts in the study phase and a parietal old/new effect confined to experts provide some proof for this hypothesis. These results coincide also with assumptions about the interaction of semantic and episodic memory made by Stenberg et al. (2008, 2009). In 
the case of existing prior knowledge (i.e., expertise), they assumed the influence of a more distinct type of semantic memory that facilitates encoding by providing links to discriminative features, which make memory representations more distinctive. This mechanism was proposed to increase hit rates for "recollect" judgments and the parietal old/new effect, as seen in our study.

Recognition memory tasks possess a further advantage over free recall tasks by allowing for the measurement of subjective memory experiences (i.e., "recollect" or "familiar" judgments). The present evidence for expertise effects in neural correlates of encoding and recognition are entirely based on differences in subjective memory judgments. The theoretical implications of our results would have been vastly diminished if an old/new recognition task, which averages across the "recollect" and "familiar" conditions in behavioral and ERP indicators, had been used. Considering the Dm results (Fig. 3), for example, averaging across ERPs for subsequently "recollected" and "familiar" cars would result in ERPs for subsequently "old" cars that were similar for experts and novices (abolishing the expertise effect on EPRs to subsequently "recollected" cars). Averaging would also lead to similar difference waves between subsequently "old" and forgotten cars for experts and novices (diminishing the expertise effect on the ERP difference between subsequent recollection and familiarity).

\section{Conclusion}

This study provides neural evidence for the assumptions about memory encoding and recognition made by previous behavioral studies and theories of expert memory (Gobet \& Simon, 1996; Rawson \& Van Overschelde, 2008). Behavioral performance and correlations between ERPs and performance show that perceptual expertise leads to better withincategory discrimination by supporting the encoding and successful recognition of more salient and distinctive object features (Goldstone, 1998; Rawson \& Van Overschelde, 2008). Results of the Dm provide evidence for the close interaction of perception and semantic knowledge during memory encoding by showing activation patterns characteristic of spontaneous and effortless deep encoding and correlations with refined perceptual processing. The parietal old/new effect, together with behavioral indices of recollection, show that expertise-related items are more successfully and consciously remembered.

The findings of the present study are new and require replication and further scrutiny, for example, with studies in which participants are trained to become experts with preexperimentally unfamiliar objects. Training studies have the advantage of directly manipulating such isolated factors as the contribution of semantic knowledge and perception to encoding processes, allowing for their influence on memory to be tested.

Acknowledgments This research was funded by NIH Grant MH64812, NSF grant \#SBE-0542013 to the Temporal Dynamics of Learning Center (an NSF Science of Learning Center), and a James S. McDonnell Foundation grant to the Perceptual Expertise Network. We thank Timothy David Freeze for language improvements, Dominika Dolzycka for helpful comments; Brent Young, Chris Bird, Colin Argys, Delora Abedzadeh, Elizabeth Eustis, Emily Kleinfelder, Megan Freeman, and Philip Jensen for research assistance.

\section{References}

Andreasen, N. C., O’Leary, D. S., Arndt, S., Cizadlo, T., Rezai, K., Watkins, G. L., et al. (1995). PET studies of memory: Novel and practiced free recall of complex narratives. Neuroimage, 2, 284-295.

Babiloni, C., Marzano, N., Infarinato, F., Iacoboni, M., Rizza, G., Aschieri, P., et al. (2010). "Neural efficiency" of experts' brain during judgment of actions: A high-resolution EEG study in elite and amateur karate athletes. Behavioural Brain Research, 207, 466-475. doi:10.1016/j.bbr.2009.10.034

Brandt, K. R., Cooper, L. M., \& Dewhurst, S. A. (2005). Expertise and recollective experience: Recognition memory for familiar and unfamiliar academic subjects. Applied Cognitive Psychology, 19, 1113-1125. doi:10.1002/acp.1163

Budson, A. E., Droller, D. B. J., Dodson, C. S., Schacter, D. L., Rugg, M. D., Holcomb, P. J., et al. (2005). Electrophysiological dissociation of picture versus word encoding: The distinctiveness heuristic as a retrieval orientation. Journal of Cognitive Neuroscience, 17, 1181-1193.

Bukach, C. M., Gauthier, I., \& Tarr, M. J. (2006). Beyond faces and modularity: The power of an expertise framework. Trends in Cognitive Sciences, 10, 159-166. doi:10.1016/j.tics.2006.02.004

Chase, W. G., \& Ericsson, K. A. (1982). Skill and working memory. In G. H. Bower (Ed.), The psychology of learning and motivation (Vol. 16). Academic Press: New York.

Chase, W. G., \& Simon, H. A. (1973). The mind's eye in chess. In W. G. Chase (Ed.), Visual information processing. New York: Academic Press.

Craik, F. I. M., \& Lockhart, R. S. (1972). Levels of processing: A framework for memory research. Journal of Verbal Learning and Verbal Behavior, 11, 671-684.

Cruse, D., \& Wilding, E. L. (2009). Prefrontal cortex contributions to episodic retrieval monitoring and evaluation. Neuropsychologia, 47, 2779-2789. doi:10.1016/j.neuropsychologia.2009.06.003

Curran, T. (2000). Brain potentials of recollection and familiarity. Memory \& Cognition, 28, 923-938.

Curran, T., \& Cleary, A. M. (2003). Using ERPs to dissociate recollection from familiarity in picture recognition. Cognitive Brain Research, 15, 191-205.

Curran, T., DeBuse, C., Woroch, B., \& Hirshman, E. (2006). Combined pharmacological and electrophysiological dissociation of familiarity and recollection. The Journal of Neuroscience, 26, 1979-1985. doi:10.1523/JNEUROSCI.5370-05.2006

De Groot, A. D. (1966). Perception and memory versus thought: Some old ideas and recent findings. In B. Kleinmutz (Ed.), Problem solving: Research, method, and theory. New York: Wiley.

Duarte, A., Ranganath, C., Winward, L., Hayward, D., \& Knigth, R. T. (2004). Dissociable neural correlates for familiarity and recollection during the encoding and retrieval of pictures. Cognitive Brain Research, 18, 255-272. doi:10.1016/j.cogbrainres.2003.10.010 
Dunn, J. C. (2004). Remember-know: A matter of confidence. Psychological Review, 111, 524-542. doi:10.1037/0033-295X.111.2.524

Ericsson, K. A., \& Kintsch, W. (1995). Long-term working memory. Psychological Review, 102, 211-245.

Friedman, D., \& Johnson, R., Jr. (2000). Event-related potential (ERP) studies of memory encoding and retrieval: A selective review. Microscopy Research and Technique, 51, 6-28.

Friedman, D., \& Trott, C. (2000). An event-related potential study of encoding in young and older adults. Neuropsychologia, 38, 542-557.

Gallo, D. A., McDonough, I. M., \& Jacon Scimeca, J. (2009). Dissociating source memory decisions in the prefrontal cortex: fMRI of diagnostic and disqualifying monitoring. Journal of Cognitive Neuroscience, 22, 955-969.

Gauthier, I., Skudlarski, P., Gore, J. C., \& Anderson, A. W. (2000). Expertise for cars and birds recruits brain areas involved in face recognition. Nature Neuroscience, 3, 191-197.

Gobet, F. (1998). Expert memory: A comparison of four theories. Cognition, 66, 115-152.

Gobet, F., \& Simon, H. A. (1996). Templates in chess memory: A mechanism for recalling several boards. Cognitive Psychology, $31,1-40$.

Goldin, S. E. (1979). Recognition memory for chess positions: Some preliminary research. The American Journal of Psychology, 92, 19-31.

Goldstone, R. L. (1998). Perceptual learning. Annual Reviews Psychology, 49, 585-612.

Graham, S., Jiang, J., Manning, V., Baladi Nejad, A., Zhisheng, K., Salleh, S. R., et al. (2010). IQ-related fMRI differences during cognitive set shifting. Cerebral Cortex, 20, 641-649. doi:10.1093/ cercor/bhp130

Green, D. M., \& Swets, J. A. (1966). Signal detection theory and psychophysics. New York: Wiley.

Gunter, T. C., Jackson, \& Mulder, G. (1992). An electrophysiological study of semantic processing in young and middle-aged academics. Psychophysiology, 29, 38-54.

Hayama, H. R., Johnson, J. D., \& Rugg, M. D. (2008). The relationship between the right frontal old/new ERP effect and post-retrieval monitoring: Specific or non-specific? Neuropsychologia, 46, 12111223. doi:10.1016/j.neuropsychologia.2007.11.021

Heinze, S., Sartory, G., Müller, B. M., de Greiff, A., Forsting, M., \& Jüptner, M. (2006). Neural encoding correlates of high and low verbal memory performance. Journal of Psychophysiology, 20, 68-78. doi:10.1027/0269-8803.20.2.68

Hintzman, D. L., \& Curran, T. (1994). Retrieval dynamics of recognition and frequency judgments: Evidence for separate processes of familiarity and recall. Journal of Memory and Language, 33, 1-18.

Horry, R., Wright, D. B., \& Tredoux, C. G. (2010). Recognition and context memory for faces from own and other ethnic groups: A remember-know investigation. Memory \& Cognition, 38, 134-141.

Jacoby, L. L. (1991). A process dissociation framework: Separating automatic from intentional uses of memory. Journal of Memory and Language, 30, 513-541.

Kawamura, S., Suzuki, S., \& Morikawa, K. (2007). The effect of expertise in hiking on recognition memory for mountain scenes. Memory, 15, 768-775.

Long, L. L., \& Prat, C. S. (2002). Memory for star trek: The role of prior knowledge in recognition revisited. Journal of Experimental Psychology. Learning, Memory, and Cognition, 28, 1073-1082.

Mandler, G. (1980). Recognizing: The judgment of previous occurrence. Psychological Review, 87, 252-271.

Marcon, J. L., Susa, K. J., \& Meissner, C. A. (2009). Assessing the influence of recollection and familiarity in memory for ownversus other-race faces. Psychonomic Bulletin \& Review, 16, 99 103. doi:10.3758/PBR.16.1.99
McGregor, S. J., \& Howes, A. (2002). The role of attack and defense semantics in skilled players' memory for chess positions. Memory \& Cognition, 30, 707-717.

Meissner, C. A., \& Brigham, J. C. (2001). Thirty years of investigating the own-race bias in memory for faces. Psychology, Public, Policy, and Law, 7, 3-35.

Meissner, C. A., Brigham, J. C., \& Butz, D. A. (2005). Memory for own- and other-race faces: A dual-process approach. Applied Cognitive Psychology, 19, 545-567. doi:10.1002/acp.1097

Motes, M. A., Malach, R., \& Kozhevnikov, M. (2008). Objectprocessing neural efficiency differentiates object from spatial visualizers. Cognitive Neuroscience and Neuropsychology, 19, 1727-1731. doi:10.1097/WNR.0b013e328317f3e2

Neubauer, A. C., \& Fing, A. (2009). Intelligence and neural efficiency. Neuroscience and Behavioral Reviews, 33, 1004-1023. doi:10.1016/j.neubiorev.2009.04.001

Nyhus, E., \& Curran, T. (2009). Semantic and perceptual effect on recognition memory: Evidence from ERP. Brain Research, 1283, 102-114. doi:10.1016/j.brainres.2009.05.091

Oldfield, R. C. (1971). The assessment and analysis of handedness: The Edinburgh inventory. Neuropsychologia, 9, 97-113.

Paller, K. A., Kutas, M., \& Mayes, A. R. (1987). Neural correlates of encoding in an incidental learning paradigm. Electroencephalography and Clinical Neurophysiology, 67, 360-371.

Paller, K. A., Kutas, M., \& McIsaac, H. K. (1995). Monitoring conscious recollection via the electrical activity of the brain. Psychological Science, 6, 107-111.

Rawson, K. A., \& Van Overschelde, J. P. (2008). How does knowledge promote memory? The distinctiveness theory of skilled memory. Journal of Memory and Language, 58, 646668. doi:10.1016/j.jml.2007.08.004

Roediger, H. L., \& McDermott, K. B. (1995). Creating false memories: Remembering words not presented in lists. Journal of Experimental Psychology: Learning, Memory, \& Cognition, $21,803-814$.

Rossion, B., \& Michel, C. (2010). An experience-based holistic account of the other-race face effect. In A. J. Calder, G. Rhodes, J. V. Haxby, \& M. H. Johnson (Eds.), The Oxford handbook of face perception. Oxford: Oxford University Press.

Rotello, C. M., Macmillan, N. A., Reeder, J. A., \& Wong, M. (2005). The remember response: Subject to bias, graded, and not a process-pure indicator of recollection. Psychonomic Bulletin \& Review, 12, 865-873.

Rugg, M. D., \& Curran, T. (2007). Event-related potentials and recognition memory. Trends in Cognitive Science, 11, 251-257. doi:10.1016/j.tics.2007.04.004

Rugg, M. D., Mark, R. E., Walla, P., Schloerscheid, A. M., Birch, C. S., \& Allan, K. (1998). Dissociation of the neural correlates of implicit and explicit memory. Nature, 392, 595-598.

Schacter, D. L., Israel, L., \& Racine, C. (1999). Suppressing false recognition in younger and older adults: The distinctiveness heuristic. Journal of Memory and Language, 40, 1-24.

Schott, B., Richardson-Klavehn, A., Heinze, H.-J., \& Düzel, E. (2002). Perceptual priming versus explicit memory: Dissociable neural correlates at encoding. Journal of Cognitive Neuroscience, 14, 578-592.

Scott, L. S., Tanaka, J. W., Sheinberg, D. L., \& Curran, T. (2008). The role of category learning in the acquisition and retention of perceptual expertise: A behavioral and neurophysiological study. Brain Research, 1210, 204-215. doi:10.1016/j. brainres.2008.02.054

Senkfor, A. J., \& Van Petten, C. (1998). Who said what? An eventrelated potential investigation of source and item memory. Journal of Experimental Psychology. Learning, Memory, and Cognition, 24, 1005-1025. 
Smith, M. E. (1993). Neurophysiological manifestations of recollective experience during recognition memory judgments. Journal of Cognitive Neuroscience, 5, 1-13.

Spaniol, J., Davidson, P. S. R., Kim, A. S. N., Han, H., Moscovitch, M., \& Grady, C. L. (2009). Event-related fMRI studies of episodic encoding and retrieval: Meta-analyses using activation likelihood estimation. Neuropsychologia, 47, 1765-1779. doi:10.1016/j.neuropsychologia.2009.02.028

Stahl, J., Wiese, H., \& Schweinberger, S. R. (2010). Learning task affects ERP-correlated of the own-race bias, but not recognition memory performance. Neuropsychologia, 48, 2027-2040. doi:10.1016/j.neuropsychologia.2010.03.024

Stenberg, G., Hellman, J., \& Johansson, M. (2008). The memorability of names and the divergent effects of prior experience. European Journal of Cognitive Psychology, 20, 312-345. doi:10.1080/ 09541440701398724

Stenberg, G., Hellman, J., Johansson, M., \& Rosén, I. (2009). Familiarity or conceptual priming: Event-related potentials in name recognition. Journal of Cognitive Neuroscience, 21, 447-460.

Tanaka, J. W. (2001). The entry point of face recognition: Evidence for face expertise. Journal of Experimental Psychology: General, 130, 534-543.

Tanaka, J. W., \& Taylor, M. (1991). Object categories and expertise: Is the basic level in the eye of the beholder? Cognitive Psychology, 23, 457-482.

Tucker, D. M. (1993). Spatial sampling of head electrical fields: the geodesic sensor net. Electroencephalography and Clinical Neurophysiology, 87, 154-163.
Voss, J. L., \& Paller, K. A. (2009). Remembering and knowing: Electrophysiological distinctions at encoding but not retrieval. Neuroimage, 46, 280-289. doi:10.1016/j.neuroimage.2009.01.048

Voss, J. L., Schendan, H. E., \& Paller, K. A. (2010). Finding meaning in novel geometric shapes influences electrophysiological correlates of repetition and dissociates perceptual and conceptual priming. Neuroimage, 49, 2879-2889. doi:10.1016/ j.neuroimage.2009.09.012

Wiese, H., Schweinberger, S. R., \& Hansen, K. (2008). The age of the beholder: ERP evidence of an own-age bias in face memory. Neuropsychologia, 46, 2973-2985. doi:10.1016/j. neuropsychologia.2008.06.007

Wilding, E. L. (2000). In what way does the parietal ERP old/new effect index recollection? International Journal of Psychophysiology, 35, $81-87$.

Wixted, J. T., \& Stretch, V. (2004). In defense of the signal-detection interpretation of remember/know judgments. Psychonomic Bulletin \& Review, 11, 616-641.

Woodruff, C. C., Hayama, H. R., \& Rugg, M. D. (2006). Electrophysiological dissociation of the neural correlates of recollection and familiarity. Brain Research, 1100, 125-135. doi:10.1016/j.brainres.2006.05.019

Yonelinas, A. P. (2001). Consciousness, control, and confidence: The 3 Cs of recognition memory. Journal of Experimental Psychology: General, 130, 361-379.

Yonelinas, A. P. (2002). The nature of recollection and familiarity: A review of 30 years of research. Journal of Memory and Language, 46, 441-517. 